\title{
Accelerated hybrid iterative algorithm for common fixed points of a finite families of countable Bregman quasi- Lipschitz mappings and solutions of generalized equilib- rium problem with application
}

\author{
Jingling Zhang ${ }^{a, *}$, Ravi P. Agarwal ${ }^{b}$, Nan Jiang $^{a, c}$ \\ ${ }^{a}$ Department of Mathematics, Tianjin University, Tianjin 300350, P. R. China. \\ ${ }^{b}$ Department of Mathematics, Texas A\&M University-Kingsville, Texas 78363, USA. \\ ${ }^{c}$ School of Mechanical Engineering, Tianjin University, Tianjin 300350, P. R. China. \\ Communicated by Y. H. Yao
}

\begin{abstract}
The purpose of this paper is to introduce and consider a new accelerated hybrid shrinking projection method for finding a common element of the set $E P \cap F$ in reflexive Banach spaces, where EP is the set of all solutions of a generalized equilibrium problem, and $\mathrm{F}$ is the common fixed point set of finite uniformly closed families of countable Bregman quasi-Lipschitz mappings. It is proved that the sequence generated by the accelerated hybrid shrinking projection iteration, converges strongly to the point in $E P \cap F$, under some conditions. This result is also applied to find the fixed point of Bregman asymptotically quasi-nonexpansive mappings. It is worth mentioning that, there are multiple projection points from the multiple points in the projection algorithm. Therefore the new projection method in this paper can accelerate the convergence speed of iterative sequence. The new results improve and extend the previously known ones in the literature.
\end{abstract}

Keywords: Bregman distance, Bregman quasi-Lipschitz mapping, accelerated hybrid algorithm, Bregman asymptotically quasi-nonexpansive mappings, equilibrium problem.

2010 MSC: 47H05, 47H09, 47H10.

(C)2018 All rights reserved.

\section{Introduction}

Takahashi et al. [30] introduced a new hybrid iterative scheme which was called shrinking projection method to approximate the common fixed point of a family of nonexpansive mappings in 2008. It is an improvement of the projection methods, because the strong convergence of iterative sequence is guaranteed without any compact assumption. Asymptotically nonexpansive mapping was firstly presented in

\footnotetext{
*Corresponding author

Email addresses: jlzhang09@tju.edu.cn (Jingling Zhang), Ravi.Agarwal@tamuk.edu (Ravi P. Agarwal), nanj@tju.edu.cn (Nan Jiang)
}

doi: $10.22436 /$ jnsa.011.01.09

Received: 2017-07-11 Revised: 2017-09-06 Accepted: 2017-09-09 
[13]. Let $C$ be a nonempty subset of a real Banach space and $T$ be a mapping from $C$ into itself. The fixed points set of $T$ is denoted by $F(T)$. A mapping $T$ is called an asymptotically nonexpansive mapping in the intermediate sense ([7]) if

$$
\limsup _{n \rightarrow \infty} \sup _{x, y \in C}\left(\left\|T^{n} x-T^{n} y\right\|-\|x-y\|\right) \leqslant 0 .
$$

In addition, $T$ is called an asymptotically quasi-nonexpansive mapping in the intermediate sense, if $F(T)$ is nonempty and for all $x \in \mathrm{C}$ and $y \in F(T),(1.1)$ holds. It is obvious that an asymptotically nonexpansive mapping must be an asymptotically nonexpansive mappings in the intermediate sense, but the converse is not always true. Since generally the mappings in the intermediate sense are not Lipschitz continuous. In uniformly convex Banach spaces, Schu [27] early introduced a modified Mann iteration to approximate the fixed point of asymptotically nonexpansive mappings. Based on [27, 30], Inchan [16] presented another hybrid iterative scheme using shrinking projection method with the modified Mann iteration for asymptotically nonexpansive mappings.

In recent years, many authors studied some other new hybrid iterative schemes in real Banach spaces; see the literature [15, 21, 32-34] for detail. In 2012, Qin and Wang [22] introduced the following new definition, asymptotically quasi-nonexpansive mappings with respect to Lyapunov functional ([1]) in the intermediate sense. In 2013, Hao [14] proved a strong convergence theorem for the new defined mapping using the shrinking projection method.

In 1967, Bregman [6] presented an elegant and effective technique, i.e., used the so-called Bregman distance function (see Section 2) to design and analyze the feasibility and optimization algorithms. It opened a growing area of research in which Bregman's technique is applied in variety of ways to design and analyze not only iterative algorithms for solving feasibility and optimization problems, but also for solving variational inequalities, computing fixed points of nonlinear mappings, and finding solutions to equilibrium problems.

Recently, many authors studied iterative algorithms for approximating fixed points of nonexpansive type mappings with respect to Bregman distance $[18,20,25,26,28]$. In [4], the authors presented a new class of nonlinear mappings, which is a generalization of asymptotically quasi-nonexpansive mappings with respect to Bregman distance in the intermediate sense. And strong convergence theorems for this new class of nonlinear mappings were also proved. In [11], the authors introduced a monotone hybrid shrinking projection method for finding a common element of the sets EP and F, where EP is the solution set of a generalized equilibrium problem, and $F$ is the common fixed point set of finite uniformly closed families of countable Bregman quasi-Lipschitz mappings in reflexive Banach spaces.

The purpose of this paper is to introduce and consider a new accelerated hybrid shrinking projection method for finding a common element of the set $E P \cap F$ in reflexive Banach spaces, where EP is the set of all solutions of a generalized equilibrium problem, and $F$ is the common fixed point set of finite uniformly closed families of countable Bregman quasi-Lipschitz mappings. It is proved that the sequence generated by the accelerated hybrid shrinking projection iteration, converges strongly to the point in EP $\cap \mathrm{F}$, under some conditions. This result is also applied to find the fixed point of Bregman asymptotically quasi-nonexpansive mappings. It is worth mentioning that, there are multiple projection points from the multiple points in the iteration algorithm. Therefore the new projection method in this paper can accelerate the convergence speed of iterative sequence. The new results improve and extend the previously known ones in the literature.

\section{Preliminaries}

We assume that $E$ is a real reflexive Banach space and $E^{*}$ is the dual space of $E$ throughout this paper. $\langle\cdot, \cdot\rangle$ is the pairing between $E$ and $E^{*}$. Let $g: E \rightarrow(-\infty,+\infty]$ be a function. As follows, dom $g$ denotes the effective domain of $\mathrm{g}$,

$$
\operatorname{dom} g:=\{x \in E: g(x)<+\infty\}
$$


We say that $\mathrm{g}$ is proper if dom $\mathrm{g} \neq \emptyset$. The interior of the effective domain of $\mathrm{g}$ is denoted by intdom $\mathrm{g}$. And the range of $g$ is denoted by ran $g$.

We say that $g$ is strongly coercive if

$$
\lim _{\|x\| \rightarrow \infty} \frac{g(x)}{\|x\|}=+\infty
$$

Given a proper and convex function $g: E \rightarrow(-\infty,+\infty]$, the subdifferential of $g$ is a mapping $\partial g: E \rightarrow E^{*}$ defined by

$$
\partial g(x)=\left\{x^{*} \in E^{*}: g(y) \geqslant g(x)+\left\langle x^{*}, y-x\right\rangle, \forall y \in E\right\},
$$

for all $x \in E$. The Fenchel conjugate function of $g$ is the convex function $g^{*}: E \rightarrow(-\infty,+\infty)$ defined by

$$
g^{*}\left(x^{*}\right)=\sup \left\{\left\langle x^{*}, x\right\rangle-g(x), x \in E\right\} .
$$

We know that the necessary and sufficient condition for $x^{*} \in \partial g(x)$ is

$$
g(x)+g^{*}\left(x^{*}\right)=\left\langle x^{*}, x\right\rangle
$$

for all $x \in E$ (see [4]).

Theorem 2.1 ([3]). Let $\mathrm{g}: \mathrm{E} \rightarrow(-\infty,+\infty]$ be a convex, proper, and lower semicontinuous function. Then the following conditions are equivalent:

(i) $g$ is strongly coercive;

(ii) on bounded subsets of $\mathrm{E}^{*}, \operatorname{ran} \partial \mathrm{g}=\mathrm{E}^{*}$ and $\partial \mathrm{g}^{*}=(\partial \mathrm{g})^{-1}$ is bounded.

Let $x \in$ intdom $g$ and $g: E \rightarrow(-\infty, \infty+]$ be a convex function. For any $y \in E$, we define the right-hand derivative of $g$ at $x$ in the direction $y$ by

$$
g^{\circ}(x, y)=\lim _{t \downarrow 0} \frac{g(x+t y)-g(x)}{t} .
$$

If the limit (2.1) exists for any $y$, we say that the function $g$ is Gâteaux differentiable at $x$. In this case, the function $\nabla g(x): E \rightarrow E^{*}$, where $\langle\nabla g(x), y\rangle=g^{\circ}(x, y)$ for all $y \in E$, is the gradient of $g$ at $x$. If the function $g$ is Gâteaux differentiable at each $x \in$ intdom $f$, then $g$ is said to be Gâteaux differentiable. The function $g$ is said to be Fréchet differentiable at $x$, if the limit (2.1) is attained uniformly in $\|y\|=1$. If the limit (2.1) is attained uniformly for $\|y\|=1$ and $x \in C$, then the function $f$ is said to be uniformly Fréchet differentiable on a subset $C$ of $E$. It is known that if $g$ is uniformly Fréchet differentiable on bounded subsets of $E$, then $g$ is uniformly continuous on bounded subsets of $E$ ([3]).

Theorem 2.2 ([23]). If a function $\mathrm{g}: \mathrm{E} \rightarrow \mathrm{R}$ is convex, bounded and uniformly Fréchet differentiable on bounded subsets of $\mathrm{E}$, then $\nabla \mathrm{g}$ is uniformly continuous on bounded subsets of $\mathrm{E}$ from the strong topology of $\mathrm{E}$ to the strong topology of $\mathrm{E}^{*}$.

Theorem 2.3 ([23]). Let $\mathrm{g}: \mathrm{E} \rightarrow \mathrm{R}$ be a convex function, which is bounded on bounded subsets of $\mathrm{E}$. Then the following assertions are equivalent:

(i) $g$ is uniformly convex and strongly coercive on bounded subsets of $\mathrm{E}$;

(ii) $\mathrm{g}^{*}$ is Fréchet differentiable and $\nabla \mathrm{g}^{*}$ is uniformly norm-to-norm continuous on bounded subsets of dom $\mathrm{g}^{*}=$ $E^{*}$. 
If a function $g: E \rightarrow(-\infty,+\infty]$ is convex, proper and lower semicontinuous on $E$ and Gâteaux differentiable on intdom $g$, then $g$ is said to be admissible. Under these conditions, we know that $g$ is continuous in intdom $g, \partial g=\nabla g$ and $\partial g$ is single-valued [20,35]. An admissible function

$$
g: E \rightarrow(-\infty,+\infty],
$$

is called Legendre ([20]) if it satisfies the following two conditions:

(L1) the interior of the domain of $g^{*}$, i.e., intdom $g^{*}$ is nonempty, $g^{*}$ is Gâteaux differentiable and dom $\nabla g^{*}=$ intdom $g^{*}$;

(L2) the interior of the domain of $g$, i.e., intdom $g$ is nonempty, $g$ is Gâteaux differentiable and dom $\nabla g=$ intdom $g$.

Let $g$ be a Legendre function on $E$. We always have $\nabla g=\left(\nabla g^{*}\right)^{-1}$ since $E$ is reflexive. When combined with conditions (L1) and (L2), this fact implies the following equalities:

$$
\operatorname{ran} \nabla \mathrm{g}=\text { dom } \mathrm{g}^{*}=\text { intdom } \mathrm{g}^{*}, \quad \operatorname{ran} \nabla \mathrm{g}^{*}=\operatorname{dom} \mathrm{g}=\text { intdom } \mathrm{g} .
$$

Conditions (L1) and (L2) imply that the functions $g$ and $g^{*}$ are strictly convex on the interior of their respective domains. The author in [31] presented an example of Legendre function.

Let $g: E \rightarrow(-\infty,+\infty]$ be a convex function on $E$ which is Gâteaux differentiable on intdom $g$. The bifunction $\mathrm{D}_{\mathrm{g}}$ : dom $\mathrm{g} \times$ intdom $\mathrm{g} \rightarrow[0,+\infty)$ denoted by

$$
D_{g}(x, y)=g(x)-g(y)-\langle x-y, \nabla g(y)\rangle,
$$

is called the Bregman distance with respect to $g$ ([10]). Generally speaking, the Bregman distance is not a metric, because it is not symmetric and does not satisfy the triangle inequality, either. However, it has the important three point identity property ([12]): for any $x \in \operatorname{dom} g$ and $y, z \in$ intdom $g$,

$$
D_{g}(x, y)+D_{g}(y, z)-D_{g}(x, z)=\langle x-y, \nabla g(z)-\nabla g(y)\rangle \text {. }
$$

With a Legendre function $g: E \rightarrow(-\infty,+\infty]$, we associate the bifunction $W_{g}:$ dom $g^{*} \times$ dom $g \rightarrow[0,+\infty)$ defined by

$$
W^{g}(w, x)=g(x)-\langle w, x\rangle+g^{*}(w) .
$$

Theorem 2.4 ([25]). Let $\mathrm{g}: \mathrm{E} \rightarrow(-\infty,+\infty]$ be a Legendre function such that $\nabla \mathrm{g}^{*}$ is bounded on bounded subsets of intdom $f^{*}$. Let $x \in$ intdom $g$. If the sequence $\left\{D_{g}\left(x, x_{n}\right)\right\}$ is bounded, then the sequence $\left\{x_{n}\right\}$ is also bounded.

Theorem 2.5 ([25]). Let $\mathrm{g}: \mathrm{E} \rightarrow(-\infty,+\infty]$ be a Legendre function. Then the following statements hold:

(i) The function $\mathrm{W}^{\mathrm{g}}(\cdot, \mathrm{x})$ is convex for all $\mathrm{x} \in \mathrm{dom} \mathrm{g}$;

(ii) $\mathrm{W}^{\mathrm{g}}(\nabla \mathrm{g}(\mathrm{x}), \mathrm{y})=\mathrm{D}_{\mathrm{g}}(\mathrm{y}, \mathrm{x})$ for all $\mathrm{x} \in$ intdom $\mathrm{g}$ and $\mathrm{y} \in$ dom $\mathrm{g}$.

Let $g: E \rightarrow(-\infty,+\infty]$ be a convex function on $E$, which is Gâteaux differentiable on intdom $g$. The modulus of total convexity at $x, v_{g}(x, \cdot):[0,+\infty) \rightarrow[0,+\infty]$ is defined as

$$
v_{g}(x, t)=\inf \left\{D_{g}(y, x): y \in \operatorname{dom} g,\|y-x\|=t\right\} .
$$

If it is positive whenever $t>0$, then the function $g$ is said to be totally convex at a point $x \in$ intdom $g$. When the function $g$ is totally convex at every point of intdom $g$, then $g$ is said to be totally convex. For any nonempty bounded set $B \subset E$, if the modulus of total convexity of $g$ on $B, v_{g}(B, t)$ is positive for any $t>0$, where $v_{g}(B, \cdot):[0,+\infty) \rightarrow[0,+\infty]$ is defined by

$$
v_{g}(B, t)=\inf \left\{v_{g}(x, t): x \in B \cap \text { intdom } g\right\},
$$

then the function $\mathrm{g}$ is said to be totally convex on bounded sets. By the way, we remark that $\mathrm{g}$ is totally convex on bounded sets if and only if $g$ is uniformly convex on bounded sets; see $[8,9]$. 
Theorem 2.6 ([8]). Let $\mathrm{g}: \mathrm{E} \rightarrow(-\infty,+\infty]$ be a convex function whose domain contains at least two points. If $\mathrm{g}$ is lower semi-continuous, then $\mathrm{g}$ is totally convex on bounded sets if and only if $\mathrm{g}$ is uniformly convex on bounded sets.

Theorem 2.7 ([24]). Let $\mathrm{g}: \mathrm{E} \rightarrow \mathrm{R}$ be a totally convex function. If $\mathrm{x} \in \mathrm{E}$ and the sequence $\left\{\mathrm{D}_{\mathrm{g}}\left(\mathrm{x}_{\mathrm{n}}, \mathrm{x}\right)\right\}$ is bounded, then the sequence $\left\{x_{n}\right\}$ is also bounded.

Let $g: E \rightarrow[0,+\infty)$ be a convex function on $E$ which is Gâteaux differentiable on intdom $g$. If for any two sequences $\left\{x_{n}\right\}$ in intdom $f$ and $\left\{y_{n}\right\}$ in dom $g,\left\{x_{n}\right\}$ is bounded, and

$$
\lim _{n \rightarrow \infty} D_{g}\left(y_{n}, x_{n}\right)=0 \Rightarrow \lim _{n \rightarrow \infty}\left\|y_{n}-x_{n}\right\|=0,
$$

then the function $g$ is said to be sequentially consistent [9].

Theorem 2.8 ([11]). A function $\mathrm{g}: \mathrm{E} \rightarrow[0,+\infty)$ is totally convex on bounded subsets of $\mathrm{E}$ if and only if it is sequentially consistent.

Let $C$ be a closed, nonempty and convex subset of $E$. Let $g: E \rightarrow(-\infty,+\infty]$ be a convex function on $E$ which is Gâteaux differentiable on intdom $g$. The Bregman projection proj ${ }_{C}^{g}(x)$ with respect to $g$ [11] of $x \in \operatorname{intdom} f$ onto $C$ is the minimizer over $C$ of the functional $D_{g}(\cdot, x): \rightarrow[0,+\infty]$, i.e.,

$$
\operatorname{proj}_{\mathrm{C}}^{\mathrm{g}}(\mathrm{x})=\operatorname{argmin}\left\{\mathrm{D}_{\mathrm{g}}(\mathrm{y}, \mathrm{x}): \mathrm{y} \in \mathrm{C}\right\} .
$$

Let $E$ be a Banach space with its dual space $E^{*}$. We denote the normalized duality mapping from $E$ to $2^{E^{*}}$ by

$$
J x=\left\{f \in E^{*}:\langle x, f\rangle=\|x\|^{2}=\|f\|^{2}\right\},
$$

where $\langle\cdot, \cdot\rangle$ is the generalized duality pairing. It is well-known that $J$ is single-value if $E$ is smooth.

Theorem 2.9 ([2]). Let $\mathrm{g}: \mathrm{E} \rightarrow \mathrm{R}$ be an admissible, strongly coercive, and strictly convex function. Let $\mathrm{C}$ be a nonempty, closed, and convex subset of dom $\mathrm{g}$. Then $\operatorname{proj}_{\mathrm{C}}^{\mathrm{g}}(\mathrm{x})$ exists uniquely for all $\mathrm{x} \in$ intdom $\mathrm{g}$.

Let $g(x)=\frac{1}{2}\|x\|^{2}$.

(i) If $\mathrm{E}$ is a Hilbert space, then the Bregman projection is reduced to the metric projection onto $\mathrm{C}$.

(ii) If $E$ is a smooth Banach space, then the Bregman projection is reduced to the generalized projection $\Pi_{C}(x)$ which is defined by

$$
\Pi_{C}(x)=\operatorname{argmin}\{\phi(y, x): y \in C\},
$$

where $\phi$ is the Lyapunov functional ([1]) defined by

$$
\phi(y, x)=\|y\|^{2}-2\langle y, J x\rangle+\|x\|^{2}
$$

for all $y, x \in E$.

Theorem 2.10 ([9]). Let $\mathrm{g}: \mathrm{E} \rightarrow(-\infty,+\infty]$ be a totally convex function. Let $\mathrm{C}$ be a nonempty, closed, and convex subset of intdom $\mathrm{g}$ and $\mathrm{x} \in$ intdom $\mathrm{g}$. If $x^{*} \in \mathrm{C}$, then the following statements are equivalent:

(i) The vector $x^{*}$ is the Bregman projection of $x$ onto $C$.

(ii) The vector $x^{*}$ is the unique solution $z$ of the variational inequality

$$
\langle z-y, \nabla g(x)-\nabla g(z)\rangle \geqslant 0, \quad \forall y \in C .
$$

(iii) The vector $x^{*}$ is the unique solution $z$ of the inequality

$$
D_{g}(y, z)+D_{g}(z, x) \leqslant D_{g}(y, x), \quad \forall y \in C .
$$


Next we present the following definitions.

Definition 2.11. Let $C$ be a nonempty, closed, and convex subset of $E$ and $g: E \rightarrow(-\infty,+\infty]$ an admissible function. Let $T$ be a mapping from $C$ into itself with nonempty fixed point set $F(T)$. The mapping $T$ is said to be Bregman quasi-Lipschitz, if there exists a constant $L \geqslant 1$ such that

$$
\mathrm{D}_{g}(\mathrm{p}, \mathrm{T} x) \leqslant \operatorname{LD}_{g}(\mathrm{p}, x), \quad \forall p \in \mathrm{F}(\mathrm{T}), \quad \forall x \in \mathrm{C} .
$$

The mapping $\mathrm{T}$ is said to be Bregman quasi-nonexpansive if

$$
\mathrm{D}_{\mathrm{g}}(\mathrm{p}, \mathrm{T} x) \leqslant \mathrm{D}_{\mathrm{g}}(\mathrm{p}, \mathrm{x}), \quad \forall \mathrm{p} \in \mathrm{F}(\mathrm{T}), \quad \forall x \in \mathrm{C} .
$$

Obviously, Bregman quasi-Lipschitz mappings is more generalized than Bregman quasi-mappings. Moreover, both the relatively quasi-Lipschitz mappings and the quasi-Lipschitz mappings are contained in the Bregman quasi-Lipschitz mappings. Therefore, we can see that Bregman quasi-Lipschitz mappings are very significant in fixed point theory and applications nonlinear analysis.

Definition 2.12. Let $C$ be a nonempty, closed, and convex subset of $E$. Let $\left\{T_{n}\right\}$ be sequence of mappings from $C$ into itself with nonempty common fixed point set $F=\cap_{n=1}^{\infty} F\left(T_{n}\right)$. The $\left\{T_{n}\right\}$ is said to be uniformly closed if for any convergent sequence $\left\{z_{n}\right\} \subset C$ such that $\left\|T_{n} z_{n}-z_{n}\right\| \rightarrow 0$ as $n \rightarrow \infty$, the limit of $\left\{z_{n}\right\}$ belongs to $F$.

Let $E$ be a real Banach space with its dual space $E^{*}$ and $C$ be a nonempty closed convex subset of $E$. Let $A: C \rightarrow E^{*}$ be a nonlinear mapping and $F: C \times C \rightarrow R$ be a bifunction. Then, consider the following generalized equilibrium problem of finding $u \in C$ such that:

$$
\mathrm{F}(\mathrm{u}, \mathrm{y})+\langle A \mathrm{u}, \mathrm{y}-\mathrm{u}\rangle \geqslant 0, \quad \forall \mathrm{y} \in \mathrm{C} .
$$

The set of solutions of (2.2) is denoted by EP, i.e.,

$$
E P=\{u \in C: F(u, y)+\langle A u, y-u\rangle \geqslant 0, \forall y \in C\} .
$$

Whenever $\mathrm{E}=\mathrm{H}$ a Hilbert space, problem (2.2) was introduced and studied by Takahashi and Takahashi [29].

Whenever $\mathrm{F} \equiv 0$, problem (1.1) is equivalent to finding $u \in C$ such that

$$
\langle A u, y-u\rangle \geqslant 0, \quad \forall y \in C,
$$

which is called the variational inequality of Browder type. The set of its solutions is denoted by $\operatorname{VI}(C, A)$.

Whenever $A \equiv 0$, problem (2.2) is equivalent to finding $u \in C$ such that

$$
\mathrm{F}(\mathrm{u}, \mathrm{y}) \geqslant 0, \forall \mathrm{y} \in \mathrm{C},
$$

which is called the equilibrium problem. The set of its solutions is denoted by $E P(F)$.

Problem (2.2) is very general in the sense that it includes, as special cases, optimization problems, variational inequalities, minimax problems, the Nash equilibrium problem in noncooperative games and others; see, e.g., $[17,19]$.

In order to solve the equilibrium problem, assume that $F: C \times C \rightarrow(-\infty,+\infty)$ satisfies the following conditions [5]:

(A1) $F(x, x)=0$ for all $x \in C$;

(A2) $F$ is monotone, i.e., $F(x, y)+F(y, x) \leqslant 0$, for all $x, y \in C$;

(A3) for all $x, y, z \in C$, limsup $\sup _{t \downarrow 0} F(t z+(1-t) x, y) \leqslant F(x, y)$; 
(A4) for all $x \in C, F(x, \cdot)$ is convex and lower semi-continuous.

For $r>0$, we define a mapping $\mathrm{K}_{\mathrm{r}}: \mathrm{E} \rightarrow \mathrm{C}$ as follows

$$
\mathrm{T}_{\mathrm{r}}(\mathrm{x})=\left\{z \in \mathrm{C}: \mathrm{F}(z, \mathrm{y})+\frac{1}{\mathrm{r}}\langle\mathrm{y}-z, \nabla \mathrm{g}(z)-\nabla \mathrm{g}(\mathrm{x})\rangle \geqslant 0, \forall \mathrm{y} \in \mathrm{C}\right\}
$$

for all $x \in E$. The following two lemmas were proved in [25].

Lemma 2.13. Let $\mathrm{E}$ be a reflexive Banach space and let $\mathrm{g}: \mathrm{E} \rightarrow \mathrm{R}$ be a Legendre function. Let $\mathrm{C}$ be a nonempty, closed and convex subset of $\mathrm{E}$ and let $\mathrm{F}: \mathrm{C} \times \mathrm{C} \rightarrow \mathrm{R}$ be a bifunction satisfying (A1)-(A4). For $\mathrm{r}>0$, let $\mathrm{T}_{\mathrm{r}}: \mathrm{E} \rightarrow \mathrm{C}$ be the mapping defined by (2.3). Then dom $\mathrm{T}_{\mathrm{r}}=\mathrm{E}$.

Lemma 2.14. Let $\mathrm{E}$ be a reflexive Banach space and let $\mathrm{f}: \mathrm{E} \rightarrow \mathrm{R}$ be a convex, continuous and strongly coercive function which is bounded on bounded subsets and uniformly convex on bounded subsets of $\mathrm{E}$. Let $\mathrm{C}$ be a nonempty, closed and convex subset of $\mathrm{E}$ and let $\mathrm{F}: \mathrm{C} \times \mathrm{C} \rightarrow \mathrm{R}$ be a bifunction satisfying (A1)-(A4). For $\mathrm{r}>0$, let $\mathrm{T}_{\mathrm{r}}: \mathrm{E} \rightarrow \mathrm{C}$ be the mapping defined by (2.3). Then the following statements hold:

(i) $\mathrm{T}_{\mathrm{r}}$ is single-valued.

(ii) $\mathrm{T}_{\mathrm{r}}$ is a firmly nonexpansive-type mapping, i.e., for all $\mathrm{x}, \mathrm{y} \in \mathrm{E}$,

$$
\left\langle\mathrm{T}_{\mathrm{r}} \mathrm{x}-\mathrm{T}_{\mathrm{r}} \mathrm{y}, \nabla \mathrm{g}\left(\mathrm{T}_{\mathrm{r}} \mathrm{x}\right)-\nabla \mathrm{g}\left(\mathrm{T}_{\mathrm{r}} \mathrm{y}\right)\right\rangle \leqslant\left\langle\mathrm{T}_{\mathrm{r}} \mathrm{x}-\mathrm{T}_{\mathrm{r}} \mathrm{y}, \nabla \mathrm{g}(\mathrm{x})-\nabla \mathrm{f}(\mathrm{y})\right\rangle .
$$

(iii) $\mathrm{F}\left(\mathrm{T}_{\mathrm{r}}\right)=\hat{\mathrm{F}}\left(\mathrm{T}_{\mathrm{r}}\right)=\mathrm{EP}(\mathrm{F})$.

(iv) $\mathrm{EP}(\mathrm{F})$ is closed and convex.

(v) $D_{g}\left(p, T_{r} x\right)+D_{g}\left(T_{r} x, x\right) \leqslant D_{g}(p, x)$, for all $p \in E P(F)$ and for all $x \in E$.

Lemma 2.15. Let $\mathrm{E}$ be a reflexive Banach space and let $\mathrm{f}: \mathrm{E} \rightarrow \mathrm{R}$ be a convex, continuous and strongly coercive function which is bounded on bounded subsets and uniformly convex on bounded subsets of $\mathrm{E}$. Let $\mathrm{C}$ be a nonempty, closed and convex subset of $\mathrm{E}$ and let $\mathrm{F}: \mathrm{C} \times \mathrm{C} \rightarrow \mathrm{R}$ be a bifunction satisfying (A1)-(A4). Let $\mathrm{A}: \mathrm{C} \rightarrow \mathrm{E}^{*}$ be $a$ monotone mapping, i.e.,

$$
\langle A x-A y, x-y\rangle \geqslant 0, \forall x, y \in C .
$$

For $\mathrm{r}>0$, let $\mathrm{K}_{\mathrm{r}}: \mathrm{E} \rightarrow \mathrm{C}$ be the mapping defined by

$$
\mathrm{K}_{\mathrm{r}}(\mathrm{x})=\left\{z \in \mathrm{C}: \mathrm{F}(z, \mathrm{y})+\langle\mathrm{A} z, \mathrm{y}-z\rangle+\frac{1}{\mathrm{r}}\langle\mathrm{y}-z, \nabla \mathrm{g}(z)-\nabla \mathrm{g}(\mathrm{x})\rangle \geqslant 0, \forall \mathrm{y} \in \mathrm{C}\right\} .
$$

Then the following statements hold:

(i) $\mathrm{K}_{\mathrm{r}}$ is single-valued.

(ii) $\mathrm{K}_{\mathrm{r}}$ is a firmly nonexpansive-type mapping, i.e., for all $\mathrm{x}, \mathrm{y} \in \mathrm{E}$,

$$
\left\langle\mathrm{K}_{\mathrm{r}} \mathrm{x}-\mathrm{K}_{\mathrm{r}} \mathrm{y}, \nabla \mathrm{g}\left(\mathrm{K}_{\mathrm{r}} \mathrm{x}\right)-\nabla \mathrm{g}\left(\mathrm{K}_{\mathrm{r}} \mathrm{y}\right)\right\rangle \leqslant\left\langle\mathrm{K}_{\mathrm{r}} \mathrm{x}-\mathrm{K}_{\mathrm{r}} \mathrm{y}, \nabla \mathrm{g}(\mathrm{x})-\nabla \mathrm{g}(\mathrm{y})\right\rangle .
$$

(iii) $F\left(K_{r}\right)=\hat{F}\left(K_{r}\right)=E P$.

(iv) EP is closed and convex.

(v) $\mathrm{D}_{\mathrm{g}}\left(\mathrm{p}, \mathrm{K}_{\mathrm{r}} \mathrm{x}\right)+\mathrm{D}_{\mathrm{g}}\left(\mathrm{K}_{\mathrm{r}} \mathrm{x}, \mathrm{x}\right) \leqslant \mathrm{D}_{\mathrm{g}}(\mathrm{p}, \mathrm{x})$, for all $\mathrm{p} \in \mathrm{EP}(\mathrm{F})$ and for all $\mathrm{x} \in \mathrm{E}$.

Proof. Let

$$
\mathrm{G}(x, y)=\mathrm{F}(\mathrm{x}, \mathrm{y})+\langle A x, y-x\rangle, \quad \forall x, y \in C .
$$

It is easy to show that, $G(x, y)$ satisfies the conditions (A1)-(A4). Replacing the $F(x, y)$ by the $G(x, y)$ in Lemma 2.14, we can get the conclusions. 


\section{Main results}

Theorem 3.1 ([11]). Let $\mathrm{g}: \mathrm{E} \rightarrow(-\infty,+\infty]$ be a Legendre function which is totally convex on bounded subsets of $\mathrm{E}$. Suppose that $\nabla \mathrm{g}^{*}$ is bounded on bounded subsets of intdom $\mathrm{g}^{*}$. Let $\mathrm{C}$ be a nonempty, closed, and convex subset of intdom g. Let $\left\{\mathrm{T}_{n}\right\}: \mathrm{C} \rightarrow \mathrm{C}$ be a uniformly closed family of countable Bregman quasi-Lipschitz mappings with the condition $\lim _{n \rightarrow \infty} \mathrm{L}_{n}=1$, where

$$
\mathrm{D}_{\mathrm{g}}\left(\mathrm{p}, \mathrm{T}_{\mathrm{n}} \mathrm{x}\right) \leqslant \mathrm{L}_{\mathrm{n}} \mathrm{D}_{\mathrm{g}}(\mathrm{p}, \mathrm{x}), \quad \forall \mathrm{p} \in \mathrm{F}, \quad \forall x \in \mathrm{C} .
$$

Let $\mathrm{F}$ be the common fixed point set of $\left\{\mathrm{T}_{\mathrm{n}}\right\}$. Then $\mathrm{F}$ is closed and convex.

Next we will prove the main strong convergence theorem for the finite families of countable Bregman quasi-Lipschitz mappings by using a new accelerated hybrid projection scheme. In this scheme, we will use some detailed technology.

Theorem 3.2. Let $\mathrm{g}: \mathrm{E} \rightarrow(-\infty,+\infty]$ be a Legendre function which is bounded, strongly coercive, uniformly Fréchet differentiable and totally convex on bounded subsets on $\mathrm{E}$. Let $\mathrm{C}$ be a nonempty, closed, and convex subset of intdom $\mathrm{f}$. Let $\left\{\mathrm{T}_{\mathrm{n}}^{(\mathfrak{i})}\right\}_{n=1}^{\infty}: \mathrm{C} \rightarrow \mathrm{C}$ be $\mathrm{N}$ uniformly closed families of countable Bregman quasi-Lipschitz mappings with the condition $\lim _{n \rightarrow \infty} L_{n}^{(i)}=1$ for $i=1,2,3, \cdots, N$. Let $F=\cap_{n=1}^{\infty} \cap_{i=1}^{N} F\left(T_{n}^{(i)}\right)$ and $F \cap E P$ be nonempty. Let $\left\{x_{n}\right\},\left\{z_{n}\right\}$ and $\left\{\omega_{n}\right\}$ be sequences of $C$ generated by

$$
\left\{\begin{array}{l}
x_{0, i}, z_{0, i} \in \text { intdom } g, \text { arbitrarily, } i=1,2, \cdots, l, \\
y_{i, n}^{(1)}=\nabla g^{*}\left(\alpha_{n}^{(1)} \nabla g\left(x_{n}\right)+\left(1-\alpha_{n}^{(1)}\right) \nabla g\left(T_{n}^{(i)} x_{n}\right)\right), i=1,2,3, \cdots, N, \\
y_{i, n}^{(2)}=\nabla g^{*}\left(\alpha_{n}^{(2)} \nabla g\left(z_{n}\right)+\left(1-\alpha_{n}^{(2)}\right) \nabla g\left(T_{n}^{(i)} z_{n}\right)\right), i=1,2,3, \cdots, N, \\
F\left(u_{i, n}^{(1)}, y\right)+\left\langle A u_{i, n}^{(1)}, y-u_{i, n}^{(1)}\right\rangle+\frac{1}{r_{n}^{(1)}}\left\langle\nabla g\left(u_{i, n}^{(1)}\right)-\nabla g\left(y_{i, n}^{(1)}\right), y-u_{i, n}^{(1)}\right\rangle \geqslant 0, \quad \forall y \in C, \\
F\left(u_{i, n}^{(2)}, y\right)+\left\langle A u_{i, n}^{(2)}, y-u_{i, n}^{(2)}\right\rangle+\frac{1}{r_{n}^{(2)}}\left\langle\nabla g\left(u_{i, n}^{(2)}\right)-\nabla g\left(y_{i, n}^{(2)}\right), y-u_{i, n}^{(2)}\right\rangle \geqslant 0, \quad \forall y \in C, \\
C_{i, n+1}^{(1)}=\left\{z \in C_{n}: D_{g}\left(z, u_{i, n}^{(1)}\right) \leqslant D_{g}\left(z, y_{i, n}^{(1)}\right) \leqslant D_{g}\left(z, x_{n}\right)+\xi_{n, i}\right\}, \\
C_{i, n+1}^{(2)}=\left\{z \in C_{n}: D_{g}\left(z, u_{i, n}^{(2)}\right) \leqslant D_{g}\left(z, y_{i, n}^{(2)}\right) \leqslant D_{g}\left(z, z_{n}\right)+\eta_{n, i}\right\} \\
C_{i, 1}^{(1)}=C_{i, 1}^{(2)}=C_{,} i=1,2,3, \cdots, N, \\
C_{n+1}^{(1)}=\cap_{i=1}^{N} C_{i, n+1}^{(1)} \\
C_{n+1}^{(2)}=\cap_{i=1}^{N} C_{i, n+1}^{(2)} \\
C_{n+1}=C_{n+1}^{(1)} \cap C_{n+1}^{(2)} \\
x_{n+1, i}=P_{C_{n+1}}^{g} x_{0, i}, i=1,2, \cdots, l \\
z_{n+1, i}=P_{C_{n+1}}^{g} z_{0, i}, i=1,2, \cdots, l \\
x_{n+1}=\sum_{i=1}^{l} \lambda_{i} x_{n+1, i}, \lambda_{i} \in[0,1] \\
z_{n+1}=\sum_{i=1}^{l} \lambda_{i} z_{n+1, i}, \lambda_{i} \in[0,1] \\
\omega_{n+1}=\lambda x_{n+1}+(1-\lambda) z_{n+1}, \lambda \in[0,1]
\end{array}\right.
$$

where

$$
\begin{aligned}
& \xi_{n, i}=\left(L_{n}-1\right) \sup _{x \in F \cap E P \cap B\left(P_{F \cap E P}^{g} x_{0, i}, 1\right)} D_{g}\left(x, x_{0, i}\right), i=1,2, \cdots, N, \\
& \eta_{n, i}=\left(L_{n}-1\right) \sup _{x \in F \cap E P \cap B\left(P_{F \cap E P}^{g} z_{0, i}, 1\right)} D_{g}\left(x, z_{0, i}\right), i=1,2, \cdots, N, \\
& B(x, 1)=\{y \in E:\|y-x\| \leqslant 1\}, \\
& L_{n}=\max \left\{L_{n}^{(1)}, L_{n}^{(2)}, L_{n}^{(3)}, \cdots, L_{n}^{(N)}\right\},
\end{aligned}
$$

$\left\{\alpha_{n}^{(1)}\right\},\left\{\alpha_{n}^{(2)}\right\}$ are sequences satisfying $\lim \sup _{n \rightarrow \infty} \alpha_{n}^{(1)}<1, \limsup _{n \rightarrow \infty} \alpha_{n}^{(2)}<1$ and $\left\{r_{n}^{(1)}\right\}$, $\left\{r_{n}^{(2)}\right\}$ are sequences satisfying $\liminf _{n \rightarrow \infty} r_{n}^{(1)}>0$, $\liminf _{n \rightarrow \infty} r_{n}^{(2)}>0$. Then the following conclusions hold: 
(1) $\left\{x_{n}\right\}$ converges strongly to $\mathrm{p}=\mathrm{P}_{\mathrm{F} \cap \mathrm{EP}}^{\mathrm{g}} \mathrm{x}_{0}$;

(2) $\left\{z_{n}\right\}$ converges strongly to $\mathrm{q}=\mathrm{P}_{\mathrm{F} \cap \mathrm{EP}}^{\mathrm{g}} z_{0}$;

(3) $\left\{\omega_{n}\right\}$ converges strongly to $\lambda q+(1-\lambda) q \in F \cap E P$.

Proof. We divide the proof into six steps.

Step 1. We show that $C_{n}$ is closed and convex for all $n \geqslant 1$. It is obvious that $C_{i, 1}^{(1)}=C$ is closed and convex for each $i=1,2,3, \cdots, N$. For each $i=1,2,3, \cdots, N$, suppose that $C_{i, k}^{(1)}$ is closed and convex for some $k \geqslant 1$. We see that,

$$
C_{i, k+1}^{(1)}=\left\{z \in C: D_{g}\left(z, u_{i, k}^{(1)}\right) \leqslant D_{g}\left(z, y_{i, k}^{(1)}\right) \leqslant D_{g}\left(z, x_{k}\right)+\xi_{k}\right\} \cap C_{i, k}^{(1)}
$$

and

$$
D_{g}\left(z, u_{i, k}^{(1)}\right) \leqslant D_{g}\left(z, y_{i, k}^{(1)}\right) \leqslant D_{g}\left(z, x_{k}\right)+\xi_{k, i}
$$

is equivalent to

$$
\left\{\begin{array}{l}
\left\langle\nabla g\left(x_{k}\right)-\nabla g\left(y_{i, k}^{(1)}\right), z\right\rangle \leqslant\left\langle g^{*}\left(\nabla g\left(x_{k}\right)\right)-g^{*}\left(\nabla g\left(y_{i, k}^{(1)}\right)\right)\right\rangle+\xi_{k, i} \\
\left\langle\nabla g\left(y_{i, k}^{(1)}\right)-\nabla g\left(u_{i, k}^{(1)}\right), z\right\rangle \leqslant\left\langle g^{*}\left(\nabla g\left(y_{i, k}^{(1)}\right)\right)-g^{*}\left(\nabla g\left(u_{i, k}^{(1)}\right)\right)\right\rangle .
\end{array}\right.
$$

Therefore,

$$
C_{i, k+1}^{(1)}=\{z \in C: z \text { satisfies }(3.1)\} \cap C_{i, k}^{(1)} .
$$

It is easy to see that, if $z_{1}, z_{2}$ satisfy (3.1), the element $z=t z_{1}+(1-t) z_{2}$ satisfies also (3.1) for all $t \in(0,1)$, so that the set

$$
\{z \in C: z \text { satisfies (3.1) }\} \text {, }
$$

is convex and closed and hence $C_{i, k+1}^{(1)}$ is closed and convex for all $n \geqslant 1$. Therefore $C_{n+1}^{(1)}=\cap_{i=1}^{N} C_{i, n+1}^{(1)}$ is closed and convex. Similarly, $C_{n+1}^{(2)}=\cap_{i=1}^{N} C_{i, n+1}^{(2)}$ is closed and convex. Hence $C_{n}$ is closed and convex for all $n \geqslant 1$.

Step 2. We show that

$$
\mathrm{F} \cap \mathrm{EP} \cap \mathrm{B}\left(\mathrm{P}_{\mathrm{F} \cap \mathrm{gP}}^{\mathrm{g}} \mathrm{x}_{0}, 1\right) \subset \mathrm{C}_{\mathrm{n}}^{(1)}
$$

and

$$
\mathrm{F} \cap \mathrm{EP} \cap \mathrm{B}\left(\mathrm{P}_{\mathrm{F} \cap \mathrm{EP}}^{\mathrm{g}} z_{0}, 1\right) \subset \mathrm{C}_{\mathrm{n}}^{(2)}
$$

for all $n \geqslant 1$. It is obvious that $F \cap E P \cap B\left(P_{F \cap E P}^{g} x_{0}, 1\right) \subset C_{i, 1}^{(1)}=C$ for all $1 \leqslant i \leqslant N$. Suppose that $F \cap E P \cap B\left(P_{F \cap E P}^{g} x_{0}, 1\right) \subset C_{i, n}^{(1)}$ for some $n \geqslant 1$. Let $p \in F \cap E P \cap B\left(P_{F \cap E P}^{g} x_{0}, 1\right)$. By Theorem 2.5, we have

$$
\begin{aligned}
D_{g}\left(p, y_{i, n}^{(1)}\right) & =D_{g}\left(p, \nabla g^{*}\left(\alpha_{n}^{(1)} \nabla g\left(x_{n}\right)+\left(1-\alpha_{n}^{(1)}\right) \nabla g\left(T_{n}^{(i)} x_{n}\right)\right)\right) \\
& =W^{g}\left(\alpha_{n}^{(1)} \nabla g\left(x_{n}\right)+\left(1-\alpha_{n}^{(1)}\right) \nabla g\left(T_{n}^{(i)} x_{n}\right), p\right) \\
& =\alpha_{n}^{(1)} W^{g}\left(\nabla g\left(x_{n}\right), p\right)+\left(1-\alpha_{n}^{(1)}\right) W^{g}\left(\nabla g\left(T_{n}^{(i)} x_{n}\right), p\right) \\
& =\alpha_{n}^{(1)} D_{g}\left(p, x_{n}\right)+\left(1-\alpha_{n}^{(1)}\right) D_{g}\left(p, T_{n}^{(i)} x_{n}\right) \\
& \leqslant \alpha_{n}^{(1)} D_{g}\left(p, x_{n}\right)+\left(1-\alpha_{n}^{(1)}\right) D_{g}\left(p, x_{n}\right)+\xi_{n} \\
& \leqslant D_{g}\left(p, x_{n}\right)+\xi_{n} .
\end{aligned}
$$

On the other hand, by Lemma 2.15, we have $p=K_{r}(p)$ and

$$
D_{g}\left(p, K_{r} y_{i, n}^{(1)}\right)+D_{g}\left(K_{n} y_{i, n}^{(1)}, y_{i, n}^{(1)}\right) \leqslant D_{g}\left(p, y_{i, n}^{(1)}\right)
$$


that is,

$$
D_{g}\left(p, u_{i, n}^{(1)}\right)+D_{g}\left(K_{n} y_{i, n}^{(1)}, y_{i, n}^{(1)}\right) \leqslant D_{g}\left(p, y_{i, n}^{(1)}\right) .
$$

Combining (3.2) and (3.3) we know that $p \in C_{i, n+1}^{(1)}$ for all $1 \leqslant i \leqslant N$, which implies that

$$
F \cap E P \cap B\left(P_{F \cap E P}^{g} x_{0}, 1\right) \subset C_{i, n+1}^{(1)} .
$$

Therefore $F \cap E P \cap B\left(P_{F \cap E P}^{g} x_{0}, 1\right) \subset C_{n+1}^{(1)}$. By induction we know that $F \cap E P \cap B\left(P F \cap{ }_{F}^{g} x_{0}, 1\right) \subset C_{n}^{(1)}$ for all $n \geqslant 1$. Similarly, $F \cap E P \cap B\left(P_{F \cap E P}^{g} z_{0}, 1\right) \subset C_{n}^{(2)}$ for all $n \geqslant 1$.

Step 3. We show that $\left\{\omega_{n}\right\}$ converges to a point of $C$.

Since $x_{n, i}=P_{C_{n}}^{g} x_{0, i}$ and $C_{n+1} \subset C_{n}$ for all $i=1,2, \cdots, l$, then we get

$$
D_{g}\left(x_{n, i}, x_{0, i}\right) \leqslant D_{g}\left(x_{n+1, i}, x_{0, i}\right), \quad \forall n \geqslant 1, \quad i=1,2, \cdots, l .
$$

Therefore $\left\{\mathrm{D}_{g}\left(x_{n, i}, x_{0, i}\right)\right\}$ is nondecreasing. On the other hand, by Definition 2.12, we have

$$
D_{g}\left(x_{n, i}, x_{0, i}\right)=D_{g}\left(P_{C_{n}}^{g} x_{0, i}, x_{0, i}\right) \leqslant D_{g}\left(p, x_{0, i}\right)-D_{g}\left(p, x_{n, i}\right) \leqslant D_{g}\left(p, x_{0, i}\right)
$$

for all $p \in F \subset C_{n}$ and for all $n \geqslant 1$. Therefore, $D_{g}\left(x_{n, i}, x_{0, i}\right)$ is also bounded. This together with (3.4) implies that the limit of $\left\{D_{g}\left(x_{n, i}, x_{0, i}\right)\right\}$ exists. Put

$$
\lim _{n \rightarrow \infty} D_{g}\left(x_{n, i}, x_{0, i}\right)=d_{i}, \quad i=1,2, \cdots, l .
$$

From Definition 2.12, we have for any positive integer $m$, that

$$
\begin{aligned}
D_{g}\left(x_{n+m, i}, x_{n, i}\right) & =D_{g}\left(x_{n+m, i}, P_{C_{n}}^{g} x_{0, i}\right) \leqslant D_{g}\left(x_{n+m, i}, x_{0, i}\right)-D_{g}\left(P_{C_{n}}^{g} x_{0, i}, x_{0, i}\right) \\
& =D_{g}\left(x_{n+m, i}, x_{0, i}\right)-D_{g}\left(x_{n, i}, x_{0, i}\right)
\end{aligned}
$$

for all $n \geqslant 1$. This together with (3.5) implies that

$$
\lim _{n \rightarrow \infty} D_{g}\left(x_{n+m, i}, x_{n, i}\right)=0,
$$

holds uniformly for all $\mathrm{m}$. Therefore, we get that

$$
\lim _{n \rightarrow \infty}\left\|x_{n+m, i}-x_{n, i}\right\|=0,
$$

holds uniformly for all $m$. Then $\left\{x_{n, i}\right\}$ is a Cauchy sequence, for all $i=1,2, \cdots, l$. Therefore there exists a point $p_{i} \in C$ such that $x_{n, i} \rightarrow p_{i}$. Similarly, $\left\{z_{n, i}\right\}$ is a Cauchy sequence, therefore there exists a point $\mathrm{q}_{i} \in \mathrm{C}$ such that $z_{n, i} \rightarrow \mathrm{q}_{i}$. Hence

$$
x_{n} \rightarrow \sum_{i=1}^{l} \lambda_{i} p_{i}=p \in C, \quad z_{n} \rightarrow \sum_{i=1}^{l} \lambda_{i} q_{i}=q \in C .
$$

From the definitions of $\omega_{n},\left\{\omega_{n}\right\}$ converges to a point $\omega=\lambda p+(1-\lambda) q \in C$.

Step 4. We show that the limit of $\left\{\omega_{n}\right\}$ belongs to $F$.

Sine $x_{n+1} \in C_{n+1}^{(1)}$, we have for all $1 \leqslant i \leqslant N$ that

$$
D_{g}\left(x_{n+1}, u_{i, n}^{(1)}\right) \leqslant D_{g}\left(x_{n+1}, y_{i, n}^{(1)}\right) \leqslant D_{g}\left(x_{n+1}, x_{n}\right)+\xi_{n} \rightarrow 0,
$$

as $n \rightarrow \infty$. By Theorem 2.8, we obtain that

$$
\lim _{n \rightarrow \infty}\left\|x_{n+1}-y_{i, n}^{(1)}\right\|=0, \quad \lim _{n \rightarrow \infty}\left\|x_{n+1}-u_{i, n}^{(1)}\right\|=0 .
$$


From

we get

$$
y_{i, n}^{(1)}=\nabla g^{*}\left(\alpha_{n}^{(1)} \nabla g\left(x_{n}\right)+\left(1-\alpha_{n}^{(1)}\right) \nabla g\left(T_{n}^{(i)} x_{n}\right)\right),
$$

where implies that

$$
\nabla \mathrm{g}\left(\mathrm{y}_{\mathrm{i}, \mathrm{n}}^{(1)}\right)=\alpha_{n}^{(1)} \nabla \mathrm{g}\left(\mathrm{x}_{\mathrm{n}}\right)+\left(1-\alpha_{n}^{(1)}\right) \nabla \mathrm{g}\left(\mathrm{T}_{n}^{(\mathrm{i})} x_{\mathrm{n}}\right)
$$

$$
\nabla g\left(y_{i, n}^{(1)}\right)-\nabla g\left(x_{n}\right)=\left(1-\alpha_{n}^{(1)}\right)\left(\nabla g\left(T_{n}^{(i)} x_{n}\right)-\nabla g\left(x_{n}\right)\right)
$$

By Theorem 2.2, we have

$$
\lim _{n \rightarrow \infty}\left\|\nabla g\left(y_{i, n}^{(1)}\right)-\nabla g\left(x_{n}\right)\right\|=0
$$

so that

$$
\lim _{n \rightarrow \infty}\left\|\nabla g\left(T_{n}^{(i)} x_{n}\right)-\nabla g\left(x_{n}\right)\right\|=0 .
$$

By Theorems 2.3 and 2.8, $\nabla g^{*}$ is uniformly continuous on bounded subsets of $E$ and thus

$$
\lim _{n \rightarrow \infty}\left\|T_{n}^{(i)} x_{n}-x_{n}\right\|=0 .
$$

Since $\left\{\mathrm{T}_{\mathfrak{n}}^{(\mathfrak{i})}\right\}$ is an asymptotically countable family of Bregman weak relatively nonexpansive mappings and $x_{n} \rightarrow p$, so that $p \in \cap_{n=1}^{\infty} F\left(T_{n}^{(i)}\right)$ for each $1 \leqslant i \leqslant N$. Therefore $p \in F=\cap_{n=1}^{\infty} \cap_{i=1}^{N} F\left(T_{n}^{(i)}\right)$. Similarly, $q \in F=\cap_{n=1}^{\infty} \cap_{i=1}^{N} F\left(T_{n}^{(i)}\right)$. Since $F$ is convex, we get $\omega \in F=\cap_{n=1}^{\infty} \cap_{i=1}^{N} F\left(T_{n}^{(i)}\right)$.

Step 5. We show that the limit of $\left\{\omega_{n}\right\}$ belongs to EP.

We have proved that $x_{n} \rightarrow p$ as $n \rightarrow \infty$. Now let us show that $p \in E P$. Since $\nabla g$ is uniformly norm-tonorm continuous on bounded subsets of $E$, from (3.6) we have $\lim _{n \rightarrow \infty}\left\|\nabla g\left(u_{i, n}^{(1)}\right)-\nabla g\left(y_{i, n}^{(1)}\right)\right\|=0$. From $\liminf _{n \rightarrow \infty} r_{n}^{(1)}>0$, it follows that

$$
\lim _{n \rightarrow \infty} \frac{\left\|\nabla g\left(u_{i, n}^{(1)}\right)-\nabla g\left(y_{i, n}^{(1)}\right)\right\|}{r_{n}^{(1)}}=0 .
$$

By the definition of $u_{n}:=K_{r_{n}} y_{n}$, we have

$$
G\left(u_{i, n}^{(1)}, y\right)+\frac{1}{r_{n}^{(1)}}\left\langle y-u_{i, n}^{(1)}, \nabla g\left(u_{i, n}^{(1)}\right)-\nabla g\left(y_{i, n}^{(1)}\right)\right\rangle \geqslant 0, \quad \forall y \in C,
$$

where

$$
G\left(u_{i, n}^{(1)}, y\right)=F\left(u_{i, n}^{(1)}, y\right)+\left\langle A u_{i, n}^{(1)}, y-u_{i, n}^{(1)}\right\rangle
$$

We have from (A2) that

$$
\frac{1}{r_{n}^{(1)}}\left\langle y-u_{i, n}^{(1)}, \nabla g\left(u_{i, n}^{(1)}\right)-\nabla g\left(y_{i, n}^{(1)}\right)\right\rangle \geqslant-G\left(u_{i, n}^{(1)}, y\right) \geqslant G\left(y, u_{i, n}^{(1)}\right), \quad \forall y \in C .
$$

Since $y \mapsto F(x, y)+\langle A x, y-x\rangle$ is convex and lower semi-continuous, letting $n \rightarrow \infty$ in the last inequality, from (A4), we have

$$
\mathrm{G}(\mathrm{y}, \mathrm{p}) \leqslant 0, \quad \forall \mathrm{y} \in \mathrm{C} .
$$

For $t$, with $0<t<1$, and $y \in C$, let $y_{t}=t y+(1-t) p$. Since $y \in C$ and $p \in C$, then $y_{t} \in C$ and hence $\mathrm{G}\left(y_{t}, p\right) \leqslant 0$. So, from (A1) we have

$$
0=G\left(y_{t}, y_{t}\right) \leqslant t G\left(y_{t}, y\right)+(1-t) G\left(y_{t}, p\right) \leqslant t G\left(y_{t}, y\right)
$$

Dividing by $t$, we have

$$
\mathrm{G}\left(\mathrm{y}_{\mathrm{t}}, \mathrm{y}\right) \geqslant 0, \quad \forall \mathrm{y} \in \mathrm{C}
$$

Letting $t \rightarrow 0$, from (A3) we can get

$$
G(p, y) \geqslant 0, \quad \forall y \in C .
$$

So, $p \in$ EP. Similarly, $q \in E P$. Therefore $\omega \in E P$. 
Step 6. Finally, we prove that $\mathrm{p}=\mathrm{P}_{\mathrm{F} \cap \mathrm{EP}}^{\mathrm{g}} \mathrm{x}_{0}$ and $\mathrm{q}=\mathrm{P}_{\mathrm{F} \cap \mathrm{EP}}^{\mathrm{g}} z_{0}$, from Definition 2.12, we have

$$
D_{g}\left(p, P_{F \cap E P}^{g} x_{0}\right)+D_{g}\left(P_{F \cap E P}^{g} x_{0}, x_{0}\right) \leqslant D_{g}\left(p, x_{0}\right) .
$$

On the other hand, since $x_{n}=P_{C_{n}}^{g} x_{0}$ and $F \cap E P \subset C_{n}$, for all $n$, and from Definition 2.12, we have

$$
D_{g}\left(P_{F \cap E P}^{g} x_{0}, x_{n+1}\right)+D_{g}\left(x_{n+1}, x_{0}\right) \leqslant D_{g}\left(P_{F \cap E P}^{g} x_{0}, x_{0}\right) \text {. }
$$

By the definition of $D_{g}(x, y)$, we know that

$$
\lim _{n \rightarrow \infty} D_{g}\left(x_{n+1}, x_{0}\right)=D_{g}\left(p, x_{0}\right) .
$$

Combining (3.7), (3.8) and (3.9), we know that $D_{g}\left(p, x_{0}\right)=D_{g}\left(P_{F \cap E P}^{g} x_{0}, x_{0}\right)$. Therefore, it follows from the uniqueness of $\mathrm{P}_{\mathrm{F} \cap E \mathrm{P}}^{\mathrm{g}} \mathrm{x}_{0}$ that $\mathrm{p}=\mathrm{P}_{\mathrm{F} \cap E \mathrm{P}}^{\mathrm{g}} \mathrm{x}_{0}$. Similarly, $\mathrm{q}=\mathrm{P}_{\mathrm{F} \cap E \mathrm{P}}^{\mathrm{g}} z_{0}$. This completes the proof.

Definition 3.3. Let $C$ be a nonempty, closed and convex subset of $E$. Let $T$ be a mapping from $C$ into itself with nonempty fixed point set $F(T)$. The mapping $T$ is said to be Lyapunov quasi-Lipschitz if there exists a constant $L \geqslant 1$ such that

$$
\phi(p, T x) \leqslant L \phi(p, x), \quad \forall p \in F(T), \quad \forall x \in C .
$$

The mapping $T$ is said to be Lyapunov quasi-nonexpansive if

$$
\phi(p, T x) \leqslant \phi(p, x), \quad \forall p \in F(T), \forall x \in C .
$$

If we choose $g(x)=\frac{1}{2}\|x\|^{2}$ for all $x \in E$, then Theorem 3.2 reduces to the following corollary.

Corollary 3.4. Let $\mathrm{E}$ be a smooth Banach space and $\mathrm{C}$ a closed convex subset of $\mathrm{E}$. Let $\left\{\mathrm{T}_{n}^{(i)}\right\}_{n=1}^{\infty}: \mathrm{C} \rightarrow \mathrm{C}$ be $\mathrm{N}$ uniformly closed families of countable Lyapunov quasi-Lipschitz mappings with the condition $\lim _{\mathfrak{n} \rightarrow \infty} \mathrm{L}_{n}^{(i)}=1$ for $i=1,2,3, \cdots, N$. Let $\mathrm{F}=\cap_{n=1}^{\infty} \cap_{i=1}^{\mathrm{N}} \mathrm{F}\left(\mathrm{T}_{\mathrm{n}}^{(i)}\right)$ and $\mathrm{F} \cap \mathrm{EP}$ be nonempty. Let $\left\{x_{n}\right\},\left\{z_{n}\right\}$ and $\left\{\omega_{n}\right\}$ be sequences of $\mathrm{C}$ generated by

$$
\left\{\begin{array}{l}
x_{0, i}, z_{0, i} \in C, \text { arbitrarily, } i=1,2, \cdots, l, \\
y_{i, n}^{(1)}=J^{-1}\left(\alpha_{n}^{(1)} J\left(x_{n}\right)+\left(1-\alpha_{n}^{(1)}\right) J\left(T_{n}^{(i)} x_{n}\right)\right), i=1,2,3, \cdots, N, \\
y_{i, n}^{(2)}=J^{-1}\left(\alpha_{n}^{(2)} J\left(z_{n}\right)+\left(1-\alpha_{n}^{(2)}\right) J\left(T_{n}^{(i)} z_{n}\right)\right), i=1,2,3, \cdots, N, \\
F\left(u_{i, n}^{(1)}, y\right)+\left\langle A u_{i, n}^{(1)}, y-u_{i, n}^{(1)}\right\rangle+\frac{1}{r_{n}^{(1)}}\left\langle J\left(u_{i, n}^{(1)}\right)-J\left(y_{i, n}^{(1)}\right), y-u_{i, n}^{(1)}\right\rangle \geqslant 0, \quad \forall y \in C, \\
F\left(u_{i, n}^{(2)}, y\right)+\left\langle A u_{i, n}^{(2)}, y-u_{i, n}^{(2)}\right\rangle+\frac{1}{r_{n}^{(2)}}\left\langle J\left(u_{i, n}^{(2)}\right)-J\left(y_{i, n}^{(2)}\right), y-u_{i, n}^{(2)}\right\rangle \geqslant 0, \quad \forall y \in C, \\
C_{i, n+1}^{(1)}=\left\{z \in C_{n}: \phi\left(z, u_{i, n}^{(1)}\right) \leqslant \phi\left(z, y_{i, n}^{(1)}\right) \leqslant \phi\left(z, x_{n}\right)+\xi_{n, i}\right\}, \\
C_{i, n+1}^{(2)}=\left\{z \in C_{n}: \phi\left(z, u_{i, n}^{(2)}\right) \leqslant \phi\left(z, y_{i, n}^{(2)}\right) \leqslant \phi\left(z, z_{n}\right)+\eta_{n, i}\right\}, \\
C_{i, 1}^{(1)}=C_{i, 1}^{(2)}=C, i=1,2,3, \cdots, N, \\
C_{n+1}^{(1)}=\cap_{i=1}^{N} C_{i, n+1}^{(1)} \\
C_{n+1}^{(2)}=\cap_{i=1}^{N} C_{i, n+1}^{(2)} \\
C_{n+1}=C_{n+1}^{(1)} \cap C_{n+1}^{(2)} \\
x_{n+1, i}=P_{C_{n+1}}^{f} x_{0, i}, i=1,2, \cdots, l \\
z_{n+1, i}=P_{C_{n+1}}^{f} z_{0, i}, i=1,2, \cdots, l \\
x_{n+1}=\sum_{i=1}^{l} \lambda_{i} x_{n+1, i}, \lambda_{i} \in[0,1] \\
z_{n+1}=\sum_{i=1}^{l} \lambda_{i} z_{n+1, i}, \lambda_{i} \in[0,1] \\
\omega_{n+1}=\lambda x_{n+1}+(1-\lambda) z_{n+1}, \lambda \in[0,1]
\end{array}\right.
$$

where

$$
\xi_{n, i}=\left(L_{n}-1\right) \sup _{x \in F \cap E P \cap B\left(P_{F \cap E P}^{f} x_{0, i}, 1\right)} \phi\left(x, x_{0, i}\right), i=1,2, \cdots, N,
$$




$$
\begin{aligned}
& \eta_{n, i}=\left(L_{n}-1\right) \sup _{x \in F \cap E P \cap B\left(P_{F \cap E P}^{f} z_{0, i}, 1\right)} \phi\left(x, z_{0, i}\right), i=1,2, \cdots, N, \\
& B(x, 1)=\{y \in E:\|y-x\| \leqslant 1\}, \\
& L_{n}=\max \left\{L_{n}^{(1)}, L_{n}^{(2)}, L_{n}^{(3)}, \ldots, L_{n}^{(N)}\right\},
\end{aligned}
$$

$\left\{\alpha_{n}^{(1)}\right\},\left\{\alpha_{n}^{(2)}\right\}$ are sequences satisfying $\limsup _{n \rightarrow \infty} \alpha_{n}^{(1)}<1, \limsup _{n \rightarrow \infty} \alpha_{n}^{(2)}<1$ and $\left\{r_{n}^{(1)}\right\},\left\{r_{n}^{(2)}\right\}$ are sequences satisfying $\liminf _{n \rightarrow \infty} r_{n}^{(1)}>0$, $\liminf _{n \rightarrow \infty} r_{n}^{(2)}>0$. Then the following conclusions hold:

(1) $\left\{x_{n}\right\}$ converges strongly to $p=\Pi_{\mathrm{F} \cap \mathrm{EP}} \mathrm{x}_{0}$;

(2) $\left\{z_{n}\right\}$ converges strongly to $q=\Pi_{\mathrm{F} \cap \mathrm{EP}} z_{0}$;

(3) $\left\{w_{n}\right\}$ converges strongly to $\lambda q+(1-\lambda) q \in F \cap E P$.

We change the structure of iterative scheme to get the following convergence theorem.

Theorem 3.5. Let $\mathrm{g}: \mathrm{E} \rightarrow(-\infty,+\infty]$ be a Legendre function which is bounded, strongly coercive, uniformly Fréchet differentiable and totally convex on bounded subsets on $\mathrm{E}$. Let $\mathrm{C}$ be a nonempty, closed, and convex subset of intdom $\mathrm{f}$. Let $\left\{\mathrm{T}_{\mathrm{n}}^{(\mathrm{i})}\right\}_{\mathfrak{n}=1}^{\infty}: \mathrm{C} \rightarrow \mathrm{C}$ be $\mathrm{N}$ uniformly closed families of countable Bregman quasi-Lipschitz mappings with the condition $\lim _{n \rightarrow \infty} L_{n}^{(i)}=1$ for $i=1,2,3, \cdots, N$. Let $F=\cap_{n=1}^{\infty} \cap_{i=1}^{N} F\left(T_{n}^{(i)}\right)$ and $F \cap E P$ be nonempty. Let $\left\{x_{n}\right\},\left\{z_{n}\right\}$ and $\left\{\omega_{n}\right\}$ be sequences of $C$ generated by

$$
\left\{\begin{array}{l}
x_{0, i}, z_{0, i} \in \text { intdom } g, \text { arbitrarily, } i=1,2, \cdots, l, \\
y_{i, n}=\nabla g^{*}\left(\alpha_{n} \nabla g\left(\omega_{n}\right)+\left(1-\alpha_{n}\right) \nabla g\left(T_{n}^{(i)} \omega_{n}\right)\right), i=1,2,3, \cdots, N, \\
F\left(u_{i, n}, y\right)+\left\langle A u_{i, n}, y-u_{i, n}\right\rangle+\frac{1}{r_{n}}\left\langle\nabla g\left(u_{i, n}\right)-\nabla g\left(y_{i, n}\right), y-u_{i, n}\right\rangle \geqslant 0, \quad \forall y \in C, \\
C_{i, n+1}=\left\{z \in C_{n}: D_{g}\left(z, u_{i, n}\right) \leqslant D_{g}\left(z, y_{i, n}\right) \leqslant D_{g}\left(z, \omega_{n}\right)+\xi_{n, i}\right\} \\
C_{i, 1}=C, i=1,2,3, \cdots, N, \\
C_{n+1}=\cap_{i=1}^{N} C_{i, n+1}, \\
x_{n+1, i}=P_{C_{n+1}}^{g} x_{0, i}, i=1,2, \cdots, l \\
z_{n+1, i}=P_{C_{n+1}}^{g} z_{0, i}, i=1,2, \cdots, l \\
x_{n+1}=\sum_{i=1}^{l} \lambda_{i} x_{n+1, i}, \lambda_{i} \in[0,1] \\
z_{n+1}=\sum_{i=1}^{l} \lambda_{i} z_{n+1, i}, \lambda_{i} \in[0,1] \\
\omega_{n+1}=\lambda x_{n+1}+(1-\lambda) z_{n+1}, \lambda \in[0,1]
\end{array}\right.
$$

where

$$
\begin{aligned}
& \xi_{n, i}=\left(L_{n}-1\right) \sup _{x \in F \cap E P \cap B\left(P_{F \cap E P}^{g} x_{0, i}, 1\right)} D_{g}\left(x, x_{0, i}\right), i=1,2, \cdots, N, \\
& B(x, 1)=\{y \in E:\|y-x\| \leqslant 1\}, \\
& L_{n}=\max \left\{L_{n}^{(1)}, L_{n}^{(2)}, L_{n}^{(3)}, \cdots, L_{n}^{(N)}\right\},
\end{aligned}
$$

$\left\{\alpha_{n}\right\}$ is a sequence satisfying $\lim \sup _{n \rightarrow \infty} \alpha_{n}<1$ and $\left\{r_{n}\right\}$ is a sequence satisfying $\lim _{n \rightarrow \infty} \inf _{n \rightarrow \infty} r_{n}>0$. Then the following conclusions hold:

(1) $\left\{x_{n}\right\}$ converges strongly to a point $p \in \cap_{n=0}^{\infty} C_{n}$;

(2) $\left\{z_{n}\right\}$ converges strongly to a point $q \in \cap_{n=0}^{\infty} C_{n}$;

(3) $\left\{\omega_{n}\right\}$ converges strongly to a point $\omega \in \mathrm{F} \cap \mathrm{EP}$.

Proof. We divide the proof into five steps. 
Step 1. We show that $C_{n}$ is closed and convex for all $n \geqslant 1$. It is obvious that $C_{i, 1}=C$ is closed and convex. Suppose that $C_{i, k}$ is closed and convex for some $k \geqslant 1$. We see for each $i=1,2,3, \cdots, N$ that,

$$
C_{i, k+1}=\left\{z \in C: D_{g}\left(z, u_{i, k}\right) \leqslant D_{g}\left(z, y_{i, k}\right) \leqslant D_{g}\left(z, \omega_{k}\right)+\xi_{k}\right\} \cap C_{i, k}
$$

and

$$
D_{g}\left(z, u_{i, k}\right) \leqslant D_{g}\left(z, y_{i, k}\right) \leqslant D_{g}\left(z, w_{k}\right)+\xi_{k},
$$

is equivalent to

$$
\left\{\begin{array}{l}
\left\langle\nabla g\left(\omega_{k}\right)-\nabla g\left(y_{i, k}\right), z\right\rangle \leqslant\left\langle g^{*}\left(\nabla g\left(w_{k}\right)\right)-g^{*}\left(\nabla g\left(y_{i, k}\right)\right)\right\rangle+\xi_{k} \\
\left\langle\nabla g\left(y_{i, k}\right)-\nabla g\left(u_{i, k}\right), z\right\rangle \leqslant\left\langle g^{*}\left(\nabla g\left(y_{i, k}\right)\right)-g^{*}\left(\nabla g\left(u_{i, k}\right)\right)\right\rangle .
\end{array}\right.
$$

Therefore,

$$
\mathrm{C}_{\mathrm{i}, \mathrm{k}+1}=\{z \in \mathrm{C}: z \text { satisfies }(3.10)\} \cap \mathrm{C}_{\mathrm{i}, \mathrm{k}} .
$$

It is easy to see that, if $z_{1}, z_{2}$ satisfy (3.10), the element $z=t z_{1}+(1-t) z_{2}$ satisfies also (3.10) for all $t \in(0,1)$, so that the set

$$
\{z \in C: z \text { satisfies }(3.10)\},
$$

is convex and closed and hence $C_{i, k+1}$ is closed and convex for all $n \geqslant 1$. Therefore $C_{n+1}=\cap \cap_{i=1}^{N} C_{i, n+1}$ is closed and convex.

Step 2. We show that $F \cap E P \cap B\left(P_{F \cap E P}^{g} x_{0}, 1\right) \subset C_{n}$ for all $n \geqslant 1$. It is obvious that

$$
\mathrm{F} \cap \mathrm{EP} \cap \mathrm{B}\left(\mathrm{P}_{\mathrm{F} \cap \mathrm{EP}}^{\mathrm{g}} \mathrm{x}_{0}, 1\right) \subset \mathrm{C}_{i, 1}=\mathrm{C}
$$

for all $1 \leqslant i \leqslant N$. Suppose that $F \cap E P \cap B\left(P_{F \cap E P}^{g} x_{0}, 1\right) \subset C_{i, n}$ for some $n \geqslant 1$. Let

$$
p \in F \cap E P \cap B\left(P_{F \cap E P}^{g} x_{0}, 1\right) \text {. }
$$

By Theorem 2.5, we have

$$
\begin{aligned}
\mathrm{D}_{g}\left(p, y_{i, n}\right) & =\mathrm{D}_{g}\left(\mathrm{p}, \nabla g^{*}\left(\alpha_{n} \nabla g\left(\omega_{n}\right)+\left(1-\alpha_{n}\right) \nabla g\left(T_{n}^{(i)} \omega_{n}\right)\right)\right) \\
& =W^{g}\left(\left(\alpha_{n} \nabla g\left(\omega_{n}\right)+\left(1-\alpha_{n}\right) \nabla g\left(T_{n}^{(i)} \omega_{n}\right), p\right)\right) \\
& =\alpha_{n} W^{g}\left(\nabla g\left(\omega_{n}\right), p\right)+\left(1-\alpha_{n}\right) W^{g}\left(\nabla g\left(T_{n}^{(i)} \omega_{n}\right), p\right) \\
& =\alpha_{n} D_{g}\left(p, \omega_{n}\right)+\left(1-\alpha_{n}\right) D_{g}\left(p, T_{n}^{(i)} \omega_{n}\right) \\
& \leqslant \alpha_{n} D_{g}\left(p, \omega_{n}\right)+\left(1-\alpha_{n}\right) D_{g}\left(p, \omega_{n}\right)+\xi_{n} \\
& \leqslant D_{g}\left(p, \omega_{n}\right)+\xi_{n} .
\end{aligned}
$$

On the other hand, by Lemma 2.15, we have $p=K_{r}(p)$ and

$$
D_{g}\left(p, K_{r} y_{i, n}\right)+D_{g}\left(K_{n} y_{i, n}, y_{i, n}\right) \leqslant D_{g}\left(p, y_{i, n}\right)
$$

that is,

$$
D_{g}\left(p, u_{i, n}\right)+D_{g}\left(K_{n} y_{i, n}, y_{i, n}\right) \leqslant D_{g}\left(p, y_{i, n}\right) .
$$

Combining (3.11) and (3.12) we know that $p \in C_{i, n+1}$ for all $1 \leqslant i \leqslant N$, which implies that

$$
\mathrm{F} \cap \mathrm{EP} \cap \mathrm{B}\left(\mathrm{P}_{\mathrm{F} \cap \mathrm{EP}}^{\mathrm{g}} \mathrm{x}_{0}, 1\right) \subset \mathrm{C}_{i, n+1} \text {. }
$$

Therefore $F \cap E P \cap B\left(P_{F \cap E P}^{g} x_{0}, 1\right) \subset C_{n+1}$. By induction we know that $F \cap E P \cap B\left(P_{F \cap E P}^{g} x_{0}, 1\right) \subset C_{n}$ for all $n \geqslant 1$. 
Step 3. We show that $\left\{x_{n}\right\}$ converges to a point $p \in \cap_{n=0}^{\infty} C_{n}$. Since $x_{n, i}=P_{C_{n}}^{g} x_{0, i}$ for all $i=1,2, \cdots, l$ and $\mathrm{C}_{\mathrm{n}+1} \subset \mathrm{C}_{\mathrm{n}}$, then we get

$$
\mathrm{D}_{\mathrm{g}}\left(\mathrm{x}_{\mathrm{n}, \mathrm{i}}, \mathrm{x}_{0, i}\right) \leqslant \mathrm{D}_{\mathrm{g}}\left(\mathrm{x}_{\mathrm{n}+1, i}, \mathrm{x}_{0, i}\right), \quad \forall \mathrm{n} \geqslant 1 \text {. }
$$

Therefore, $\left\{D_{g}\left(x_{n, i}, x_{0, i}\right)\right\}$ is nondecreasing. On the other hand, by Definition 2.12, we have

$$
D_{g}\left(x_{n, i}, x_{0, i}\right)=D_{g}\left(P_{C_{n}}^{g} x_{0, i}, x_{0, i}\right) \leqslant D_{g}\left(p, x_{0, i}\right)-D_{g}\left(p, x_{n, i}\right) \leqslant D_{g}\left(p, x_{0, i}\right)
$$

for all $p \in F \subset C_{n}$ and for all $n \geqslant 1$. Therefore, $D_{g}\left(x_{n, i}, x_{0, i}\right)$ is also bounded. This together with (3.13) implies that the limit of $\left\{\mathrm{D}_{g}\left(\mathrm{x}_{n, i}, \mathrm{x}_{0, i}\right)\right\}$ exists. Put

$$
\lim _{n \rightarrow \infty} D_{g}\left(x_{n, i}, x_{0, i}\right)=d_{i}
$$

From Definition 2.12, we have, for any positive integer $m$ that

$$
\begin{aligned}
D_{g}\left(x_{n+m, i}, x_{n, i}\right) & =D_{g}\left(x_{n+m, i}, P_{C_{n}}^{g} x_{0, i}\right) \leqslant D_{g}\left(x_{n+m, i}, x_{0, i}\right)-D_{g}\left(P_{C_{n}}^{g} x_{0, i}, x_{0, i}\right) \\
& =D_{g}\left(x_{n+m, i}, x_{0, i}\right)-D_{g}\left(x_{n, i}, x_{0, i}\right)
\end{aligned}
$$

for all $n \geqslant 1$. This together with (3.14) implies that

$$
\lim _{n \rightarrow \infty} D_{g}\left(x_{n+m, i}, x_{n, i}\right)=0,
$$

holds uniformly for all $\mathrm{m}$. Therefore, we get that

$$
\lim _{n \rightarrow \infty}\left\|x_{n+m, i}-x_{n, i}\right\|=0,
$$

holds uniformly for all $m$. Then $\left\{x_{n, i}\right\}$ is a Cauchy sequence for all $i=1,2, \cdots, l$. Therefore there exists a point $p_{i} \in C$ such that $x_{n, i} \rightarrow p_{i}$. Similarly, $\left\{z_{n, i}\right\}$ is a Cauchy sequence, therefore there exists a point $\mathrm{q}_{i} \in \mathrm{C}$ such that $z_{n, i} \rightarrow \mathrm{q}_{i}$. Hence

$$
x_{n} \rightarrow \sum_{i=1}^{l} \lambda_{i} p_{i}=p \in C, \quad z_{n} \rightarrow \sum_{i=1}^{l} \lambda_{i} q_{i}=q \in C .
$$

From the definitions of $\omega_{n},\left\{\omega_{n}\right\}$ converges to a point $\omega=\lambda p+(1-\lambda) q \in C$.

Next, we prove that $p \in \cap_{n=0}^{\infty} C_{n}$. In fact, for any $C_{n}$, we have that, $x_{n+m} \in C_{n}$ for all $m \geqslant 1$ and $x_{n+m} \rightarrow p$ as $m \rightarrow \infty$. Since $C_{n}$ is closed, we have $p \in C_{n}$. Therefore $p \in \cap_{n=0}^{\infty} C_{n}$. Similarly, $\mathrm{q} \in \cap_{\mathrm{n}=0}^{\infty} \mathrm{C}_{\mathrm{n}}$.

Step 4 . We show that the limit of $\left\{\omega_{n}\right\}$ belongs to F. Since

$$
\omega_{n+1}=\lambda x_{n+1}+(1-\lambda) z_{n+1} \in C_{n+1}, \quad \omega_{n} \rightarrow \lambda p+(1-\lambda) q,
$$

we have for all $1 \leqslant i \leqslant N$ that

$$
D_{g}\left(\omega_{n+1}, u_{i, n}\right) \leqslant D_{g}\left(\omega_{n+1}, y_{i, n}\right) \leqslant D_{g}\left(\omega_{n+1}, \omega_{n}\right)+\xi_{n} \rightarrow 0,
$$

as $n \rightarrow \infty$. By Theorem 2.8, we obtain that

$$
\lim _{n \rightarrow \infty}\left\|\omega_{n+1}-y_{i, n}\right\|=0, \lim _{n \rightarrow \infty}\left\|\omega_{n+1}-u_{i, n}\right\|=0 .
$$

From

$$
y_{i, n}=\nabla g^{*}\left(\alpha_{n} \nabla g\left(\omega_{n}\right)+\left(1-\alpha_{n}\right) \nabla f\left(T_{n}^{(i)} \omega_{n}\right)\right),
$$

we get

$$
\nabla g\left(y_{i, n}\right)=\alpha_{n} \nabla g\left(\omega_{n}\right)+\left(1-\alpha_{n}\right) \nabla g\left(T_{n}^{(i)} \omega_{n}\right),
$$


where implies that

$$
\nabla g\left(y_{i, n}\right)-\nabla g\left(\omega_{n}\right)=\left(1-\alpha_{n}\right)\left(\nabla g\left(T_{n}^{(i)} \omega_{n}\right)-\nabla g\left(\omega_{n}\right)\right)
$$

By Theorem 2.2, we have

$$
\lim _{n \rightarrow \infty}\left\|\nabla g\left(y_{i, n}\right)-\nabla g\left(\omega_{n}\right)\right\|=0
$$

so that

$$
\lim _{n \rightarrow \infty}\left\|\nabla g\left(T_{n}^{(i)} \omega_{n}\right)-\nabla g\left(\omega_{n}\right)\right\|=0 .
$$

By Theorems 2.3 and 2.8, $\nabla f^{*}$ is uniformly continuous on bounded subsets of $E$ and thus

$$
\lim _{n \rightarrow \infty}\left\|T_{n}^{(i)} \omega_{n}-\omega_{n}\right\|=0
$$

Since $\left\{T_{n}^{(i)}\right\}$ is uniformly closed for each $1 \leqslant i \leqslant N$, and $\omega_{n} \rightarrow \omega=\lambda p+(1-\lambda) q$, so that $\omega \in \cap_{n=1}^{\infty} F\left(T_{n}^{(i)}\right)$ for each $1 \leqslant i \leqslant N$. Therefore $\omega \in F=\cap_{n=1}^{\infty} \cap_{i=1}^{N} F\left(T_{n}^{(i)}\right)$.

Step 5. We show that the limit of $\left\{\omega_{n}\right\}$ belongs to EP.

We have proved that $\omega_{n} \rightarrow \omega$ as $n \rightarrow \infty$. Now let us show that $\omega \in E P$. Since $\nabla f$ is uniformly normto-norm continuous on bounded subsets of $E$, from (3.15) we have $\lim _{n \rightarrow \infty}\left\|\nabla g\left(u_{i, n}\right)-\nabla g\left(y_{i, n}\right)\right\|=0$. From $\liminf _{n \rightarrow \infty} r_{n}>0$, it follows that

$$
\lim _{n \rightarrow \infty} \frac{\left\|\nabla g\left(u_{i, n}\right)-\nabla g\left(y_{i, n}\right)\right\|}{r_{n}}=0
$$

By the definition of $u_{n}:=K_{r_{n}} y_{n}$, we have

$$
G\left(u_{i, n}, y\right)+\frac{1}{r_{n}}\left\langle y-u_{i, n}, \nabla g\left(u_{i, n}\right)-\nabla g\left(y_{i, n}\right)\right\rangle \geqslant 0, \quad \forall y \in C,
$$

where

$$
G\left(u_{i, n}, y\right)=F\left(u_{i, n}, y\right)+\left\langle A u_{i, n}, y-u_{i, n}\right\rangle
$$

We have from (A2) that

$$
\frac{1}{r_{n}}\left\langle y-u_{i, n}, \nabla g\left(u_{i, n}\right)-\nabla g\left(y_{i, n}\right)\right\rangle \geqslant-G\left(u_{i, n}, y\right) \geqslant G\left(y, u_{i, n}\right), \quad \forall y \in C .
$$

Since $y \mapsto F(x, y)+\langle A x, y-x\rangle$ is convex and lower semi-continuous, letting $n \rightarrow \infty$ in the last inequality, from (A4) and (3.15), we have

$$
G(y, w) \leqslant 0, \quad \forall y \in C .
$$

For $t$, with $0<t<1$, and $y \in C$, let $y_{t}=t y+(1-t) \omega$. Since $y \in C$ and $\omega \in C$, then $y_{t} \in C$ and hence $\mathrm{G}\left(\mathrm{y}_{\mathrm{t}}, \omega\right) \leqslant 0$. So, from $(\mathrm{A} 1)$ we have

$$
0=G\left(y_{t}, y_{t}\right) \leqslant t G\left(y_{t}, y\right)+(1-t) G\left(y_{t}, w\right) \leqslant t G\left(y_{t}, y\right)
$$

Dividing by $t$, we have

$$
G\left(y_{t}, y\right) \geqslant 0, \quad \forall y \in C
$$

Letting $t \rightarrow 0$, from (A3) we can get

$$
G(\omega, y) \geqslant 0, \quad \forall y \in C
$$

So, $\omega \in$ EP. This completes the proof.

If we choose $g(x)=\frac{1}{2}\|x\|^{2}$ for all $x \in E$, then Theorem 3.5 reduces to the following corollary. 
Corollary 3.6. Let $\mathrm{E}$ be a smooth Banach space and $\mathrm{C}$ a closed convex subset of $\mathrm{E}$. Let $\left\{\mathrm{T}_{n}^{(i)}\right\}_{n=1}^{\infty}: \mathrm{C} \rightarrow \mathrm{C}$ be $\mathrm{N}$ uniformly closed families of countable Lyapunov quasi-Lipschitz mappings with the condition $\lim _{n \rightarrow \infty} \mathrm{L}_{n}^{(i)}=1$ for $i=1,2,3, \cdots, N$. Let $\mathrm{F}=\cap_{n=1}^{\infty} \cap_{i=1}^{\mathrm{N}} \mathrm{F}\left(\mathrm{T}_{\mathrm{n}}^{(i)}\right)$ and $\mathrm{F} \cap \mathrm{EP}$ be nonempty. Let $\left\{x_{n}\right\},\left\{z_{n}\right\}$ and $\left\{\omega_{n}\right\}$ be sequences of $\mathrm{C}$ generated by

$$
\left\{\begin{array}{l}
x_{0, i}, z_{0, i} \in C, \text { arbitrarily, } i=1,2, \cdots, l, \\
y_{i, n}=J^{-1}\left(\alpha_{n} J \omega_{n}+\left(1-\alpha_{n}\right) J T_{n}^{(i)} \omega_{n}\right), i=1,2,3, \cdots, N, \\
F\left(u_{i, n}, y\right)+\left\langle A u_{i, n}, y-u_{i, n}\right\rangle+\frac{1}{r_{n}}\left\langle J u_{i, n}-J y_{i, n}, y-u_{i, n}\right\rangle \geqslant 0, \quad \forall y \in C, \\
C_{i, n+1}=\left\{z \in C_{n}: \phi\left(z, u_{i, n}\right) \leqslant \phi\left(z, y_{i, n}\right) \leqslant \phi\left(z, \omega_{n}\right)+\xi_{n}\right\} \\
C_{i, 1}=C, i=1,2,3, \cdots, N \\
C_{n+1}=\cap_{i=1}^{N} C_{i, n+1}, \\
x_{n+1, i}=P_{C_{n+1}}^{f} x_{0, i}, i=1,2, \cdots, l \\
z_{n+1, i}=P_{C_{n+1}}^{f} z_{0, i}, i=1,2, \cdots, l \\
x_{n+1}=\sum_{i=1}^{l} \lambda_{i} x_{n+1, i}, \lambda_{i} \in[0,1] \\
z_{n+1}=\sum_{i=1}^{l} \lambda_{i} z_{n+1, i}, \lambda_{i} \in[0,1] \\
\omega_{n+1}=\lambda x_{n+1}+(1-\lambda) z_{n+1}, \lambda \in[0,1]
\end{array}\right.
$$

where

$$
\begin{aligned}
& \xi_{n, i}=\left(L_{n}-1\right) \sup _{x \in \operatorname{F\cap EP} \cap B\left(P_{\mathrm{F} \cap E P}^{f} x_{0}, 1\right)} \phi\left(x, x_{0}\right), i=1,2, \cdots, N, \\
& B(x, 1)=\{y \in E:\|y-x\| \leqslant 1\}, \\
& L_{n}=\max \left\{L_{n}^{(1)}, L_{n}^{(2)}, L_{n}^{(3)}, \cdots, L_{n}^{(N)}\right\},
\end{aligned}
$$

$\left\{\alpha_{n}\right\}$ is a sequence satisfying $\limsup _{n \rightarrow \infty} \alpha_{n}<1$ and $\left\{r_{n}\right\}$ is a sequence satisfying $\lim _{n \rightarrow \infty} \inf _{n \rightarrow \infty}>0$. Then the following conclusions hold:

(1) $\left\{x_{n}\right\}$ converges strongly to a point $p \in \cap_{n=0}^{\infty} C_{n}$;

(2) $\left\{z_{n}\right\}$ converges strongly to a point $\mathrm{q} \in \cap_{n=0}^{\infty} \mathrm{C}_{n}$;

(3) $\left\{\omega_{n}\right\}$ converges strongly to a point $\omega \in \mathrm{F} \cap \mathrm{EP}$.

Taking $\lambda \equiv 1$ in Theorem 3.5 and Corollary 3.6, we obtain the following results.

Corollary 3.7. Let $\mathrm{g}: \mathrm{E} \rightarrow(-\infty,+\infty]$ be a Legendre function which is bounded, strongly coercive, uniformly Fréchet differentiable and totally convex on bounded subsets on $\mathrm{E}$. Let $\mathrm{C}$ be a nonempty, closed, and convex subset of intdom $\mathrm{f}$. Let $\left\{\mathrm{T}_{\mathrm{n}}^{(\mathrm{i})}\right\}_{\mathfrak{n}=1}^{\infty}: \mathrm{C} \rightarrow \mathrm{C}$ be $\mathrm{N}$ uniformly closed families of countable Bregman quasi-Lipschitz mappings with the condition $\lim _{n \rightarrow \infty} L_{n}^{(i)}=1$ for $i=1,2,3, \cdots, N$. Let $\mathrm{F}=\cap_{n=1}^{\infty} \cap_{i=1}^{N} F\left(T_{n}^{(i)}\right)$ and $\mathrm{F} \cap \mathrm{EP}$ be nonempty. Let $\left\{x_{n}\right\},\left\{z_{n}\right\}$ and $\left\{\omega_{n}\right\}$ be sequences of $C$ generated by

$$
\left\{\begin{array}{l}
x_{0, i} \in \text { intdom g, arbitrarily, } i=1,2, \cdots, l, \\
y_{i, n}=\nabla g^{*}\left(\alpha_{n} \nabla g\left(x_{n}\right)+\left(1-\alpha_{n}\right) \nabla g\left(T_{n}^{(i)} x_{n}\right)\right), i=1,2,3, \cdots, N, \\
F\left(u_{i, n}, y\right)+\left\langle A u_{i, n}, y-u_{i, n}\right\rangle+\frac{1}{r_{n}}\left\langle\nabla g\left(u_{i, n}\right)-\nabla g\left(y_{i, n}\right), y-u_{i, n}\right\rangle \geqslant 0, \quad \forall y \in C, \\
C_{i, n+1}=\left\{z \in C_{n}: D_{g}\left(z, u_{i, n}\right) \leqslant D_{g}\left(z, y_{i, n}\right) \leqslant D_{g}\left(z, x_{n}\right)+\xi_{n, i}\right\}, \\
C_{i, 1}=C, i=1,2,3, \cdots, N, \\
C_{n+1}=\cap_{i=1}^{N} C_{i, n+1}, \\
x_{n+1, i}=P_{C_{n+1}}^{g} x_{0, i}, i=1,2, \cdots, l, \\
x_{n+1}=\sum_{i=1}^{l} \lambda_{i} x_{n+1, i}, \lambda_{i} \in[0,1],
\end{array}\right.
$$


where

$$
\begin{aligned}
& \xi_{n, i}=\left(L_{n}-1\right) \sup _{x \in F \cap E P \cap B\left(P_{F \cap E P}^{g} x_{0, i}, 1\right)} D_{g}\left(x, x_{0, i}\right), i=1,2, \cdots, N, \\
& B(x, 1)=\{y \in E:\|y-x\| \leqslant 1\}, \\
& L_{n}=\max \left\{L_{n}^{(1)}, L_{n}^{(2)}, L_{n}^{(3)}, \cdots, L_{n}^{(N)}\right\},
\end{aligned}
$$

$\left\{\alpha_{n}\right\}$ is a sequence satisfying $\limsup _{n \rightarrow \infty} \alpha_{n}<1$ and $\left\{r_{n}\right\}$ is a sequence satisfying $\lim _{n \rightarrow \infty} r_{n}>0$. Then $\left\{x_{n}\right\}$ converges strongly to a point $p \in F \cap E P$.

Letting $g(x)=\frac{1}{2}\|x\|^{2}$ in Corollary 3.7, we get the following result.

Corollary 3.8. Let $\mathrm{E}$ be a smooth Banach space and $\mathrm{C}$ a closed convex subset of $\mathrm{E}$. Let $\left\{\mathrm{T}_{\mathrm{n}}^{(\mathrm{i})}\right\}_{\mathrm{n}=1}^{\infty}: \mathrm{C} \rightarrow \mathrm{C}$ be $\mathrm{N}$ uniformly closed families of countable Lyapunov quasi-Lipschitz mappings with the condition $\lim _{n \rightarrow \infty} \mathrm{L}_{n}^{(i)}=1$ for $i=1,2,3, \cdots, N$. Let $\mathrm{F}=\cap_{n=1}^{\infty} \cap_{i=1}^{\mathrm{N}} \mathrm{F}\left(\mathrm{T}_{\mathrm{n}}^{(i)}\right)$ and $\mathrm{F} \cap \mathrm{EP}$ be nonempty. Let $\left\{x_{n}\right\},\left\{z_{n}\right\}$ and $\left\{\omega_{n}\right\}$ be sequences of $\mathrm{C}$ generated by

$$
\left\{\begin{array}{l}
x_{0, i} \in \text { intdom } f, \text { arbitrarily, } i=1,2, \cdots, l \\
y_{i, n}=J^{-1}\left(\alpha_{n} J x_{n}+\left(1-\alpha_{n}\right) J T_{n}^{(i)} x_{n}\right), i=1,2,3, \cdots, N, \\
F\left(u_{i, n}, y\right)+\left\langle A u_{i, n}, y-u_{i, n}\right\rangle+\frac{1}{r_{n}}\left\langle J u_{i, n}-J y_{i, n}, y-u_{i, n}\right\rangle \geqslant 0, \quad \forall y \in C, \\
C_{i, n+1}=\left\{z \in C_{n}: \phi\left(z, u_{i, n}\right) \leqslant \phi\left(z, y_{i, n}\right) \leqslant \phi\left(z, x_{n}\right)+\xi_{n, i}\right\}, \\
C_{i, 1}=C, i=1,2,3, \cdots, N \\
C_{n+1}=\cap_{i=1}^{N} C_{i, n+1}, \\
x_{n+1, i}=P_{C_{n+1}}^{f} x_{0, i}, i=1,2, \cdots, l \\
x_{n+1}=\sum_{i=1}^{l} \lambda_{i} x_{n+1, i}, \lambda_{i} \in[0,1]
\end{array}\right.
$$

where

$$
\begin{aligned}
& \xi_{n, i}=\left(L_{n}-1\right) \sup _{x \in F \cap E P \cap B\left(P_{F \cap E P}^{f} x_{0, i}, 1\right)} \phi\left(x, x_{0, i}\right), i=1,2, \cdots, N, \\
& B(x, 1)=\{y \in E:\|y-x\| \leqslant 1\}, \\
& L_{n}=\max \left\{L_{n}^{(1)}, L_{n}^{(2)}, L_{n}^{(3)}, \ldots, L_{n}^{(N)}\right\},
\end{aligned}
$$

$\left\{\alpha_{n}\right\}$ is a sequence satisfying $\limsup _{n \rightarrow \infty} \alpha_{n}<1$ and $\left\{r_{n}\right\}$ is a sequence satisfying $\liminf _{n \rightarrow \infty} r_{n}>0$. Then $\left\{x_{n}\right\}$ converges strongly to a point $\mathrm{p} \in \mathrm{F} \cap \mathrm{EP}$.

Letting $l=1$ in Corollary 3.7 and Corollary 3.8 respectively, we get the following results.

Corollary 3.9. Let $\mathrm{g}: \mathrm{E} \rightarrow(-\infty,+\infty)$ be a Legendre function which is bounded, strongly coercive, uniformly Fréchet differentiable and totally convex on bounded subsets on $\mathrm{E}$. Let $\mathrm{C}$ be a nonempty, closed, and convex subset of intdom $\mathrm{f}$. Let $\left\{\mathrm{T}_{\mathrm{n}}^{(i)}\right\}_{\mathfrak{n}=1}^{\infty}: \mathrm{C} \rightarrow \mathrm{C}$ be $\mathrm{N}$ uniformly closed families of countable Bregman quasi-Lipschitz mappings with the condition $\lim _{n \rightarrow \infty} L_{n}^{(i)}=1$ for $i=1,2,3, \cdots, N$. Let $F=\cap_{n=1}^{\infty} \cap_{i=1}^{N} F\left(T_{n}^{(i)}\right)$ and $F \cap E P$ be nonempty. Let $\left\{x_{n}\right\},\left\{z_{n}\right\}$ and $\left\{\omega_{n}\right\}$ be sequences of $C$ generated by

$$
\left\{\begin{array}{l}
x_{0} \in \text { intdom } g, \text { arbitrarily, } \\
y_{i, n}=\nabla g^{*}\left(\alpha_{n} \nabla g\left(x_{n}\right)+\left(1-\alpha_{n}\right) \nabla g\left(T_{n}^{(i)} x_{n}\right)\right), i=1,2,3, \cdots, N, \\
F\left(u_{i, n}, y\right)+\left\langle A u_{i, n}, y-u_{i, n}\right\rangle+\frac{1}{r_{n}}\left\langle\nabla g\left(u_{i, n}\right)-\nabla g\left(y_{i, n}\right), y-u_{i, n}\right\rangle \geqslant 0, \quad \forall y \in C, \\
C_{i, n+1}=\left\{z \in C_{n}: D_{g}\left(z, u_{i, n}\right) \leqslant D_{g}\left(z, y_{i, n}\right) \leqslant D_{g}\left(z, x_{n}\right)+\xi_{n}\right\}, \\
C_{i, 1}=C, i=1,2,3, \cdots, N, \\
C_{n+1}=\cap_{i=1}^{N} C_{i, n+1}, \\
x_{n+1}=P_{C_{n+1}}^{g} x_{0},
\end{array}\right.
$$


where

$$
\begin{aligned}
& \xi_{n}=\left(L_{n}-1\right) \sup _{x \in F \cap E P \cap B\left(P_{F \cap E P}^{g} x_{0}, 1\right)} D_{g}\left(x, x_{0}\right), \\
& B(x, 1)=\{y \in E:\|y-x\| \leqslant 1\}, \\
& L_{n}=\max \left\{L_{n}^{(1)}, L_{n}^{(2)}, L_{n}^{(3)}, \ldots, L_{n}^{(N)}\right\},
\end{aligned}
$$

$\left\{\alpha_{n}\right\}$ is a sequence satisfying $\lim \sup _{n \rightarrow \infty} \alpha_{n}<1$ and $\left\{r_{n}\right\}$ is a sequence satisfying $\lim _{n \rightarrow \infty} r_{n}>0$. Then $\left\{x_{n}\right\}$ converges strongly to a point $\mathrm{p} \in \mathrm{P}_{\mathrm{F} \cap \mathrm{EP}}^{\mathrm{g}} \mathrm{x}_{0}$.

Proof. By using Theorem 3.5, we know that, the iterative sequence $\left\{x_{n}=\omega_{n}\right\}$ converges strongly to a point $\omega \in F \cap E P$. Next, we prove that $\omega=P_{F \cap E P}^{g} x_{0}$, from Theorem 2.10, we have

$$
D_{g}\left(p, P_{F \cap E P}^{g} x_{0}\right)+D_{g}\left(P_{F \cap E P}^{g} x_{0}, x_{0}\right) \leqslant D_{g}\left(\omega, x_{0}\right) .
$$

On the other hand, since $\omega_{n}=P_{C_{n}}^{f} x_{0}$ and F.EP $\subset C_{n}$, for all $n$, and from Theorem 2.10, we have

$$
D_{g}\left(P_{F \cap E P}^{g} x_{0}, \omega_{n+1}\right)+D_{g}\left(\omega_{n+1}, x_{0}\right) \leqslant D_{g}\left(P_{F \cap E P}^{g} x_{0}, x_{0}\right) .
$$

By the definition of $D_{g}(x, y)$, we know that

$$
\lim _{n \rightarrow \infty} D_{g}\left(\omega_{n+1}, x_{0}\right)=D_{g}\left(\omega, x_{0}\right) .
$$

Combining (3.16), (3.17) and (3.18), we know that $\mathrm{D}_{g}\left(\omega, x_{0}\right)=\mathrm{D}_{\mathrm{g}}\left(\mathrm{P}_{\mathrm{F} \cap \mathrm{EP}}^{\mathrm{g}} \mathrm{x}_{0}, \mathrm{x}_{0}\right)$. Therefore, it follows from the uniqueness of $\mathrm{P}_{\mathrm{F} \cap E \mathrm{P}}^{\mathrm{g}} \mathrm{x}_{0}$ that $\omega=\mathrm{P}_{\mathrm{F} \cap E \mathrm{P}}^{\mathrm{g}} \mathrm{x}_{0}$. This completes the proof.

Letting $g(x)=\frac{1}{2}\|x\|^{2}$ in Corollary 3.9, we get the following result.

Corollary 3.10. Let $\mathrm{E}$ be a smooth Banach space and $\mathrm{C}$ a closed convex subset of $\mathrm{E}$. Let $\left\{\mathrm{T}_{\mathrm{n}}^{(\mathrm{i})}\right\}_{\mathrm{n}=1}^{\infty}: \mathrm{C} \rightarrow \mathrm{C}$ be $\mathrm{N}$ uniformly closed families of countable Lyapunov quasi-Lipschitz mappings with the condition $\lim _{n \rightarrow \infty} \mathrm{L}_{n}^{(i)}=1$ for $i=1,2,3, \cdots, N$. Let $\mathrm{F}=\cap_{n=1}^{\infty} \cap_{i=1}^{\mathrm{N}} \mathrm{F}\left(\mathrm{T}_{\mathrm{n}}^{(i)}\right)$ and $\mathrm{F} \cap \mathrm{EP}$ be nonempty. Let $\left\{x_{n}\right\},\left\{z_{n}\right\}$ and $\left\{\omega_{n}\right\}$ be sequences of $\mathrm{C}$ generated by

$$
\left\{\begin{array}{l}
x_{0} \in C, \text { arbitrarily, } \\
y_{i, n}=J^{-1}\left(\alpha_{n} J x_{n}+\left(1-\alpha_{n}\right) J T_{n}^{(i)} x_{n}\right), i=1,2,3, \cdots, N, \\
F\left(u_{i, n}, y\right)+\left\langle A u_{i, n}, y-u_{i, n}\right\rangle+\frac{1}{r_{n}}\left\langle J u_{i, n}-J y_{i, n}, y-u_{i, n}\right\rangle \geqslant 0, \quad \forall y \in C \\
C_{i, n+1}=\left\{z \in C_{n}: \phi\left(z, u_{i, n}\right) \leqslant \phi\left(z, y_{i, n}\right) \leqslant \phi\left(z, x_{n}\right)+\xi_{n}\right\} \\
C_{i, 1}=C, i=1,2,3, \cdots, N \\
C_{n+1}=\cap_{i=1}^{N} C_{i, n+1} \\
x_{n+1}=P_{C_{n+1}}^{f} x_{0}
\end{array}\right.
$$

where

$$
\begin{aligned}
& \xi_{n}=\left(L_{n}-1\right) \sup _{x \in F \cap E P \cap B\left(P_{F \cap E P}^{f} x_{0}, 1\right)} \phi\left(x, x_{0}\right), \\
& B(x, 1)=\{y \in E:\|y-x\| \leqslant 1\}, \\
& L_{n}=\max \left\{L_{n}^{(1)}, L_{n}^{(2)}, L_{n}^{(3)}, \cdots, L_{n}^{(N)}\right\},
\end{aligned}
$$

$\left\{\alpha_{n}\right\}$ is a sequence satisfying $\lim \sup _{n \rightarrow \infty} \alpha_{n}<1$ and $\left\{r_{n}\right\}$ is a sequence satisfying $\liminf _{n \rightarrow \infty} r_{n}>0$. Then $\left\{x_{n}\right\}$ converges strongly to a point $\mathrm{p} \in \Pi_{\mathrm{F} \cap \mathrm{EP}} \mathrm{x}_{0}$. 
Proof. By using Corollary 3.6, we know that, the iterative sequence $\left\{x_{n}=\omega_{n}\right\}$ converges strongly to a point $\omega \in F \cap E P$. Next, we prove that $\omega=\Pi_{F \cap E P} x_{0}$, from Theorem 2.10, we have

$$
\phi\left(p, \Pi_{F \cap E P} x_{0}\right)+\phi\left(\Pi_{F \cap E P} x_{0}, x_{0}\right) \leqslant \phi\left(\omega, x_{0}\right) .
$$

On the other hand, since $\omega_{n}=\Pi_{C_{n}} x_{0}$ and F.EP $\subset C_{n}$, for all $n$, and from Theorem 2.10, we have

$$
\phi\left(\Pi_{\mathrm{F} \cap \mathrm{EP}} \mathrm{x}_{0}, \omega_{\mathrm{n}+1}\right)+\phi\left(\omega_{n+1}, \mathrm{x}_{0}\right) \leqslant \phi\left(\Pi_{\mathrm{F} \cap \mathrm{EP}} \mathrm{x}_{0}, \mathrm{x}_{0}\right) .
$$

By the definition of $\phi(x, y)$, we know that

$$
\lim _{n \rightarrow \infty} \phi\left(\omega_{n+1}, x_{0}\right)=\phi\left(\omega, x_{0}\right)
$$

Combining (3.19), (3.20) and (3.21), we know that $\phi\left(\omega, x_{0}\right)=\phi\left(\Pi_{\mathrm{F} \cap \mathrm{EP}} \mathrm{x}_{0}, x_{0}\right)$. Therefore, it follows from the uniqueness of $\Pi_{\mathrm{F} \cap E \mathrm{P}} \mathrm{X}_{0}$ that $\omega=\Pi_{\mathrm{F} \cap E \mathrm{P}} \mathrm{X}_{0}$. This completes the proof.

Remark 3.11. In 2015, Chen et al. [11] have given some examples of uniformly closed family of countable Bregman quasi-Lipschitz mappings.

\section{Application}

The mapping $T$ is said to be Bregman asymptotically quasi-nonexpansive ([23]) if $F(T) \neq \emptyset$ and there exists a sequence $\left\{k_{n}\right\} \subset[1,+\infty)$ with $\lim _{n \rightarrow \infty} k_{n}=1$ such that

$$
\mathrm{D}_{g}\left(\mathrm{p}, \mathrm{T}^{\mathrm{n}} \mathrm{x}\right) \leqslant \mathrm{k}_{\mathrm{n}} \mathrm{D}_{\mathrm{g}}(\mathrm{p}, \mathrm{x}), \quad \forall \mathrm{p} \in \mathrm{F}(\mathrm{T}), \forall x \in \mathrm{C} .
$$

Every Bregman quasi-nonexpansive mapping is Bregman asymptotically quasi-nonexpansive with $k_{n} \equiv$ 1. Let $S_{n}=T^{n}$ for all $n \geqslant 1$, the above inequality become

$$
\mathrm{D}_{\mathrm{g}}\left(\mathrm{p}, \mathrm{S}_{\mathrm{n}} \mathrm{x}\right) \leqslant \mathrm{k}_{\mathrm{n}} \mathrm{D}_{\mathrm{g}}(\mathrm{p}, \mathrm{x}), \quad \forall \mathrm{p} \in \mathrm{F}(\mathrm{T}), \forall x \in \mathrm{C} .
$$

It is obvious that $\cap_{n=1}^{\infty} F\left(S_{n}\right)=\cap_{n=1}^{\infty} F\left(T^{n}\right)=F(T)$.

Lemma 4.1. Assume $\mathrm{T}$ is uniformly Lipschitz, that is, there exists a constant $\mathrm{L} \geqslant 1$ such that

$$
\left\|T^{n} x-T^{n} y\right\| \leqslant L\|x-y\|, \quad \forall x, y \in C,
$$

for all $\mathrm{n} \geqslant 1$. Then $\left\{\mathrm{S}_{\mathrm{n}}\right\}=\left\{\mathrm{T}^{\mathrm{n}}\right\}$ is uniformly closed.

Proof. Assume $\left\|z_{n}-S_{n} z_{n}\right\| \rightarrow 0, z_{n} \rightarrow p$ as $n \rightarrow \infty$, we have $\left\|z_{n}-T^{n} z_{n}\right\| \rightarrow 0$, therefore

$$
\left\|p-T^{n} p\right\| \leqslant\left\|p-T^{n} z_{n}\right\|+\left\|T^{n} z_{n}-T^{n} p\right\| \leqslant\left\|p-T^{n} z_{n}\right\|+L\left\|z_{n}-p\right\| \rightarrow 0,
$$

as $n \rightarrow \infty$. One hand, $T^{n} p \rightarrow p$, other hand, $T^{n+1} p \rightarrow T p$, these imply that $p=T p$. Hence $p \in \cap_{n=1}^{\infty} F\left(S_{n}\right)$. This completes the proof.

Next we give an application of Theorem 3.2 to find the fixed point of Bregman asymptotically quasinonexpansive mappings.

Theorem 4.2. Let $\mathrm{g}: \mathrm{E} \rightarrow(-\infty,+\infty]$ be a Legendre function which is bounded, strongly coercive, uniformly Fréchet differentiable and totally convex on bounded subsets on $\mathrm{E}$. Let $\mathrm{C}$ be a nonempty, closed, and convex subset of intdom $\mathrm{f}$. Let $\left\{\mathrm{T}_{i}\right\}_{i=1}^{\mathrm{N}}: \mathrm{C} \rightarrow \mathrm{C}$ be $\mathrm{N}$ uniformly Lipschitz Bregman asymptotically quasi-nonexpansive mappings 
with nonempty common fixed point set $\mathrm{F}=\cap_{i=1}^{\mathrm{N}} \mathrm{F}\left(\mathrm{T}_{i}\right)$ and $\mathrm{F} \cap \mathrm{EP}$ be nonempty. Let $\left\{x_{n}\right\},\left\{z_{n}\right\}$ and $\left\{\omega_{n}\right\}$ be sequences of $\mathrm{C}$ generated by

$$
\left\{\begin{array}{l}
x_{0, i}, z_{0, i} \in \text { intdom } g, \text { arbitrarily, } i=1,2, \cdots, l, \\
y_{i, n}^{(1)}=\nabla g^{*}\left(\alpha_{n}^{(1)} \nabla g\left(x_{n}\right)+\left(1-\alpha_{n}^{(1)}\right) \nabla g\left(T_{i}^{n} x_{n}\right)\right), i=1,2,3, \cdots, N, \\
y_{i, n}^{(2)}=\nabla g^{*}\left(\alpha_{n}^{(2)} \nabla g\left(z_{n}\right)+\left(1-\alpha_{n}^{(2)}\right) \nabla g\left(T_{i}^{n} z_{n}\right)\right), i=1,2,3, \cdots, N, \\
F\left(u_{i, n}^{(1)}, y\right)+\left\langle A u_{i, n}^{(1)}, y-u_{i, n}^{(1)}\right\rangle+\frac{1}{r_{n}^{(1)}}\left\langle\nabla g\left(u_{i, n}^{(1)}\right)-\nabla g\left(y_{i, n}^{(1)}\right), y-u_{i, n}^{(1)}\right\rangle \geqslant 0, \quad \forall y \in C, \\
F\left(u_{i, n}^{(2)}, y\right)+\left\langle A u_{i, n}^{(2)}, y-u_{i, n}^{(2)}\right\rangle+\frac{1}{r_{n}^{(2)}}\left\langle\nabla g\left(u_{i, n}^{(2)}\right)-\nabla g\left(y_{i, n}^{(2)}\right), y-u_{i, n}^{(2)}\right\rangle \geqslant 0, \quad \forall y \in C, \\
C_{i, n+1}^{(1)}=\left\{z \in C_{n}: D_{g}\left(z, u_{i, n}^{(1)}\right) \leqslant D_{g}\left(z, y_{i, n}^{(1)}\right) \leqslant D_{g}\left(z, x_{n}\right)+\xi_{n, i}\right\}, \\
C_{i, n+1}^{(2)}=\left\{z \in C_{n}: D_{g}\left(z, u_{i, n}^{(2)}\right) \leqslant D_{g}\left(z, y_{i, n}^{(2)}\right) \leqslant D_{g}\left(z, z_{n}\right)+\eta_{n, i}\right\}, \\
C_{i, 1}^{(1)}=C_{i, 1}^{(2)}=C_{,} i=1,2,3, \cdots, N, \\
C_{n+1}^{(1)}=\cap_{i=1}^{N} C_{i, n+1}^{(1)} \\
C_{n+1}^{(2)}=\cap_{i=1}^{N} C_{i, n+1}^{(2)} \\
C_{n+1}=C_{n+1}^{(1)} \cap C_{n+1}^{(2)} \\
x_{n+1, i}=P_{C_{n+1}}^{g} x_{0, i}, i=1,2, \cdots, l, \\
z_{n+1, i}=P_{C_{n+1}}^{g} z_{0, i}, i=1,2, \cdots, l, \\
x_{n+1}=\sum_{i=1}^{l} \lambda_{i} x_{n+1, i}, \lambda_{i} \in[0,1], \\
z_{n+1}=\sum_{i=1}^{l} \lambda_{i} z_{n+1, i}, \lambda_{i} \in[0,1], \\
\omega_{n+1}=\lambda x_{n+1}+(1-\lambda) z_{n+1}, \lambda \in[0,1],
\end{array}\right.
$$

where

$$
\begin{aligned}
& \xi_{n, i}=\left(L_{n}-1\right) \sup _{x \in F \cap E P \cap B\left(P_{F \cap E P}^{g} x_{0, i}, 1\right)} D_{g}\left(x, x_{0, i}\right), i=1,2, \cdots, N, \\
& \eta_{n, i}=\left(L_{n}-1\right) \sup _{x \in F \cap E P \cap B\left(P_{F \cap E P}^{g} z_{0, i}, 1\right)} D_{g}\left(x, z_{0, i}\right), i=1,2, \cdots, N, \\
& B(x, 1)=\{y \in E:\|y-x\| \leqslant 1\}, \\
& L_{n}=\max \left\{L_{n}^{(1)}, L_{n}^{(2)}, L_{n}^{(3)}, \cdots, L_{n}^{(N)}\right\},
\end{aligned}
$$

$\left\{\alpha_{n}^{(1)}\right\},\left\{\alpha_{n}^{(2)}\right\}$ are sequences satisfying $\lim \sup _{n \rightarrow \infty} \alpha_{n}^{(1)}<1, \limsup _{n \rightarrow \infty} \alpha_{n}^{(2)}<1$ and $\left\{r_{n}^{(1)}\right\},\left\{r_{n}^{(2)}\right\}$ are sequences satisfying $\lim \inf _{n \rightarrow \infty} r_{n}^{(1)}>0$, $\liminf _{n \rightarrow \infty} r_{n}^{(2)}>0$. Then the following conclusions hold:

(1) $\left\{x_{n}\right\}$ converges strongly to $\mathrm{p}=\mathrm{P}_{\mathrm{F} \cap \mathrm{EP}}^{\mathrm{g}} \mathrm{x}_{0}$;

(2) $\left\{z_{n}\right\}$ converges strongly to $\mathrm{q}=\mathrm{P}_{\mathrm{F} \cap \mathrm{EP}}^{\mathrm{g}} z_{0}$;

(3) $\left\{\omega_{n}\right\}$ converges strongly to $\lambda q+(1-\lambda) q \in F \cap E P$.

Proof. Let $\mathrm{T}_{\mathfrak{n}}^{\mathrm{i}}=\mathrm{T}_{i}^{\mathrm{n}}$ for all $\mathrm{n} \geqslant 1, i=1,2,3, \cdots, \mathrm{N}$. By using Lemma 4.1 and Theorem 3.2 we can obtain the conclusion.

\section{Acknowledgment}

The first author gratefully acknowledges the financial support from the China Scholarship Council. This work also has been supported by the National Natural Science Foundation of China (Grant No. $11332006,11272233,11572221$ ), the National key basic research and development program (plan 973) (No. 2012CB720101, No. 2012CB720103). 


\section{References}

[1] Y. I. Alber, Metric and generalized projection operators in Banach spaces: properties and applications. In: Kartsatos, AG (ed.) Theory and Applications of Nonlinear Operators of Accretive and Monotone Type, Lecture Notes Pure Appl. Math., 178 (1996), 15-50. 1, 2

[2] Y. Alber, D. Butnariu, Convergence of Bregman projection methods for solving consistent convex feasibility problems in reflexive Banach spaces, J. Optim. Theory Appl., 92 (1997), 33-61. 2.9

[3] V. Barbu, T. Precupanu, Convexity and Optimization in Banach Spaces, Springer, Dordrecht, (2012). 2.1, 2

[4] H. H. Bauschke, J. M. Borwein, P. L. Combettes, Essential smoothness, essential strict convexity, and Legendre functions in Banach spaces, Commun. Contemp. Math., 3 (2001), 615-647. 1, 2

[5] E. Blum, W. Oettli, From optimization and variational inequalities to equilibrium problems, Math. Student, 63 (1994), 123-145. 2

[6] L. M. Bregman, The relaxation method of finding the common point of convex sets and its application to the solution of problems in convex programming, USSR Comput. Math. Math. Phys., 7 (1967), 200-217. 1

[7] R. Bruck, T. Kuczumow, S. Reich, Convergence of iterates of asymptotically nonexpansive mappings in Banach spaces with the uniform Opial property, Colloq. Math., 65 (1993), 169-179. 1

[8] D. Butnariu, A. N. Iusem, C. Zălinescu, On uniform convexity, total convexity and convergence of the proximal points and outer Bregman projection algorithms in Banach spaces, J. Convex Anal., 10 (2003), 35-61. 2, 2.6

[9] D. Butnariu, E. Resmerita, Bregman distances, totally convex functions, and a method for solving operator equations in Banach spaces, Abstr. Appl. Anal., 2006 (2006), 39 pages. 2, 2, 2.10

[10] Y. Censor, A. Lent, An iterative row-action method for interval convex programming, J. Optim. Theory Appl., 34 (1981), 321-353. 2

[11] M. Chen, J. Bi, Y. Su, Hybrid iterative algorithm for finite families of countable Bregman quasi-Lipschitz mappings with applications in Banach spaces, J. Inequal. Appl., 2015 (2015), 19 pages. 1, 2.8, 2, 3.1, 3.11

[12] G. Chen, M. Teboulle, Convergence analysis of a proximal-like minimization algorithm using Bregman functions, SIAM J. Optim., 3 (1993), 538-543. 2

[13] K. Goebel, W. A. Kirk, A fixed point theorem for asymptotically nonexpansive mappings, Proc. Amer. Math. Soc., 35 (1972), 171-174. 1

[14] Y. Hao, Some results on a modified Mann iterative scheme in a reflexive Banach space, Fixed Point Theory Appl., 2013 (2013), 14 pages. 1

[15] Y. Hecai, L. Aichao, Projection algorithms for treating asymptotically quasi- $\phi$-nonexpansive mappings in the intermediate sense, J. Inequal. Appl., 2013 (2013), 15 pages. 1

[16] I. Inchan, Strong convergence theorems of modified Mann iteration methods for asymptotically nonexpansive mappings in Hilbert spaces, Int. J. Math. Anal., 2 (2008), 1135-1145. 1

[17] F. Kohsaka, W. Takahashi, Strong convergence of an iterative sequence for maximal monotone operators in a Banach space, Abstr. Appl. Anal., 3 (2004), 239-249. 2

[18] V. Martín-Márquez, S. Reich, S. Sabach, Iterative methods for approximating fixed points of Bregman nonexpansive operators, Discrete Contin. Dyn. Syst. Ser. S, 6 (2013), 1043-1063. 1

[19] B. Martinet, Regularisation d'inequations variationnelles par approximations successives, Rev. Franaise Informat. Recherche Oprationnelle, 4 (1970), 154-158. 2

[20] E. Naraghirad, J.-C. Yao, Bregman weak relatively nonexpansive mappings in Banach spaces, Fixed Point Theory Appl., 2013 (2013), 43 pages. 1, 2

[21] X. Qin, S. Huang, T. Wang, On the convergence of hybrid projection algorithms for asymptotically quasi- $\phi$-nonexpansive mappings, Comput. Math. Appl., 61 (2011), 851-859. 1

[22] X. Qin, L. Wang, On asymptotically quasi- $\phi$-nonexpansive mappings in the intermediate sense, Abstr. Appl. Anal., 2012 (2012), 13 pages. 1

[23] S. Reich, S. Sabach, A strong convergence theorem for a proximal-type algorithm in reflexive Banach spaces, J. Nonlinear Convex Anal., 10 (2009), 471-485. 2.2, 2.3, 4

[24] S. Reich, S. Sabach, Two strong convergence theorems for a proximal method in reflexive Banach spaces, Numer. Funct. Anal. Optim., 31 (2010), 22-44. 2.7

[25] S. Reich, S. Sabach, Two strong convergence theorems for Bregman strongly nonexpansive operators in reflexive Banach spaces, Nonlinear Anal., 73 (2010), 122-135. 1, 2.4, 2.5, 2

[26] S. Reich, S. Sabach, Existence and approximation of fixed points of Bregman firmly nonexpansive mappings in reflexive Banach spaces. In: Fixed-Point Algorithms for Inverse Problems in Science and Engineering, Springer Optim. Appl., 49 (2011), 301-316. 1

[27] J. Schu, Weak and strong convergence to fixed points of asymptotically nonexpansive mappings, Bull. Austral. Math. Soc., 43 (1991), 153-159. 1

[28] S. Suantai, Y. J. Cho, P. Cholamjiak, Halpern's iteration for Bregman strongly nonexpansive mappings in reflexive Banach spaces, Comput. Math. Appl., 64 (2012), 489-499. 1

[29] S. Takahashi, W. Takahashi, Strong convergence theorem for a generalized equilibrium problem and a nonexpansive mapping in a Hilbert space, Nonlinear Anal., 69 (2008), 1025-1033. 2 
[30] W. Takahashi, Y. Takeuchi, R. Kubota, Strong convergence theorems by hybrid methods for families of nonexpansive mappings in Hilbert spaces, J. Math. Anal. Appl., 341 (2008), 276-286. 1, 1

[31] Y. Tomizawa, A strong convergence theorem for Bregman asymptotically quasi-nonexpansive mappings in the intermediate sense, Fixed Point Theory Appl., 2014 (2014), 14 pages. 2

[32] Y.-H. Yao, M. Postolache, S. M. Kang, Strong convergence of approximated iterations for asymptotically pseudocontractive mappings, Fixed Point Theory Appl., 2014 (2014), 13 pages. 1

[33] Y.-H. Yao, N. Shahzad, Y.-C. Liou, Modified semi- implicit midpoint rule for nonexpansive mappings, Fixed Point Theory Appl., 2015 (2015), 15 pages.

[34] Q. Yuan, Some results on asymptotically quasi-ф-nonexpansive mappings in the intermediate sense, J. Fixed Point Theory, 2012 (2012), Article ID 1. 1

[35] C. Zălinescu, Convex Analysis in General Vector Spaces, World Scientific, River Edge, (2002). 2 